\title{
Capítulo
}

1

\section{Technology Roadmap (TRM) e suas aplicações em Sistemas de Informação}

\section{Technology Roadmap (TRM) and its applications in Information Systems}

Márcia França Ribeiro, Renata Mendes de Araujo

\begin{abstract}
The purpose of this chapter is to motivate and teach students, researchers and professionals in Information Systems to use the Technology Roadmapping Method (TRM), a technology-prospecting tool which helps organizations to identify innovation opportunities in their products and services over a long-term horizon. The chapter presents concepts about innovation and its processes, the role of TRM in innovation processes, the step-by-step method itself, and its importance in guiding professionals and researchers to identify and plan innovation opportunities in their innovation projects and research, in particular in the area of Information System. The chapter was constructed based on studies on innovation in IS postgraduate level and on practical experience of applying TRM in the last years.
\end{abstract}

\section{Resumo}

O objetivo deste capitulo é apresentar aos estudantes, pesquisadores e profissionais na área de Sistemas de Informação o uso do Método Technology Roadmapping (TRM), uma ferramenta de prospecção tecnológica que apoia as organizações a identificar oportunidades de inovação em seus produtos e serviços em um horizonte de longo prazo. O capitulo apresenta os conceitos sobre inovação e seus processos, o papel do TRM nos processos de inovação, o passo a passo do método em si, e sua importância em nortear profissionais e pesquisadores a identificarem e planejarem oportunidades de inovação em seus projetos e pesquisas, em particular na área de Sistema de Informação. O capítulo foi construído com base nos estudos sobre inovação em disciplinas de pós-graduação em SI e em experiências práticas de aplicação do TRM nos últimos anos. 


\subsection{Introdução}

A prospecção tecnológica é o termo utilizado para os estudos que têm por finalidade antecipar e entender as potencialidades, evolução, características e efeitos das mudanças tecnológicas, particularmente a sua invenção, inovação, adoção e uso (Coates et al., 2001). O monitoramento dessas informações oferece vantagens competitivas às organizações, no sentido de estabelecerem seus planos estratégicos visando a inovação e a introdução de novos produtos no mercado.

Araújo \& Chueri (2018) defendem a complementariedade dos processos de pesquisa científica e os processos de inovação tecnológica. Enquanto a pesquisa científica instrumenta o pesquisador com métodos que garantem rigor e visa a geração de conhecimento para comunidades científicas, a inovação confere visão aplicada a problemas reais e a desafios para o desenvolvimento de soluções. A combinação destes processos pode alavancar tanto a geração de conhecimento científico com visão aplicada, particularmente importante para a área de Sistemas de Informação, como a produção de artefatos inovadores baseados em pesquisa científica.

A busca e prospecção de informação tecnológica são etapas importante nos dois processos (Araújo \& Chueri, 2018). São fundamentais no processo de inovação tecnológica, como também têm se tornado cada vez mais importantes no processo de produção científica, haja vista que a compreensão do "estado da técnica" em uma determinada área também passa pela identificação do conhecimento tecnológico disponível.

Segundo Nunes \& Pinheiro-Machado (2017), para oportunizar a produção de um novo produto ou processo advindo de uma pesquisa científica ou da inovação tecnológica, é importante utilizar a prospecção tecnológica para esclarecer questões como: “i) A tecnologia que será produzida é uma inovação? ii) A tecnologia já foi disponibilizada comercialmente? Ela já foi patenteada? Foi ou está sendo comercializada? iii) Se a tecnologia já foi patenteada, quais as lacunas existentes nessa tecnologia? iv) Se a tecnologia não foi patenteada, será que a mesma tem mercado e é passível de interesse nos processos produtivos locais, regionais ou nacionais?"

Considerando o aumento do interesse e prática de geração de conhecimento (tanto científico como tecnológico) em todo mundo na forma de patentes, estimulados por políticas públicas internacionais (Araújo \& Paula, 2017), a busca de informação tecnológica torna-se uma atividade importante cujo conteúdo não pode ser negligenciado tanto por pesquisadores como empreendedores. A partir desta constatação, a questão que se coloca é como realizar esta busca. A proposta que apresentaremos neste minicurso é a aplicação de roadmaps (Phaal et al, 2004).

As aplicações dos roadmaps incluem desde pesquisas científicas de ciência e tecnologia, previsão para políticas governamentais ou para determinado setor industrial, até estudos da evolução de produtos ou tecnologias. A literatura técnica apresenta exemplos de sucesso de desenvolvimento e aplicação de roadmaps em diversas áreas da ciência, tecnologia e indústria. Alguns roadmaps encontrados não apenas fazem previsões, como também definem barreiras de natureza tecnológica que precisam ser vencidas. Há, em alguns casos, propostas de ações para fomentar e estimular o setor de estudo, identificando os responsáveis por tais ações e estabelecendo um horizonte de tempo para a tomada das mesmas. Neste contexto, o uso de roadmaps no planejamento 
estratégico das linhas de pesquisa realizadas em empresas, startups, universidades ou grupos de pesquisa, em especial na área de Sistemas de Informação (SI), podem auxiliar na identificação de áreas de pesquisa e/ou desenvolvimento tecnológico, bem como identificar os principais players visando a propor parcerias estratégicas entre estas organizações.

O objetivo deste capítulo, portanto, é apresentar uma ferramenta de prospecção tecnológica, o Technology Roadmap (TRM) (Phaal et al. 2001, 2004) e um método para construí-la. Objetiva também demonstrar as implicações dos dados coletados com o uso desta ferramenta para a geração de conhecimento e concepção de soluções para as pesquisas na área de SI. Para isso, o capítulo aborda: na Seção 2, o conceito e o processo de inovação; na Seção 3, o conceito de prospecção tecnológica e as fontes principais de informação tecnológica; a Seção 4 apresenta o TRM e sua capacidade de integrar e comunicar as estratégias de desenvolvimento de mercado, produto e tecnologia com as metas ao longo do tempo; na Seção 5, é apresentado um método de aplicação da construção de roadmap tecnológico em projetos na área de Sistema de Informação; e, por fim, na Seção 6, são apresentadas conclusões.

\subsection{Inovação}

Desde as épocas mais antigas, as inovações já haviam chamado a atenção de vários estudiosos; entretanto, a obra do economista austríaco Joseph Schumpeter, datada do início do século XX, é considerada um marco sob a perspectiva econômica e empresarial. "Para esse autor inovação é sinônimo de progresso econômico e consiste essencialmente na alocação de recursos produtivos em usos ainda não experimentados" (Schumpeter, 1971 apud Barbieri, 2007). Ainda segundo Schumpeter (1984 apud Burlamarqui \& Proença, 2003 p. 82-83) “(...) o impulso fundamental que inicia e mantém a máquina capitalista em movimento decorre dos novos bens de consumo, dos novos métodos de produção ou transporte, dos novos mercados, das novas formas de organização industrial que a empresa capitalista cria (...)".

Cabe destacar que a inovação não se resume somente à geração de novas ideias, pois requer a criação ou a invenção de algo novo e a sua posterior aplicação na própria organização ou no mercado. Isto constitui a principal diferença entre a invenção e a inovação: enquanto a primeira é independente do uso, a inovação pressupõe a utilização da criação ou invenção no contexto interno ou externo a organizações. Se a invenção não demonstrar utilidade, não pode ser classificada como inovação (Freire, 1998). Tigre (2006 p. 72) aponta que "a invenção se refere à criação de um processo, técnica ou produto inédito", podendo ser divulgada através de artigos técnicos e científicos ou registrada sob a forma de patente, sem, contudo, apresentar uma aplicação comercial efetiva. "Já $a$ inovação ocorre com a efetiva aplicação prática de uma invenção" (Tigre 2006 p.72).

\subsubsection{Tipos de inovação}

Uma primeira forma de compreender a inovação é pelo seu objeto. Segundo Schumpeter (apud: Tidd, Bessant \& Pavitt 2008), por exemplo, uma inovação pode compreender: i) a introdução de um novo produto no mercado ou a mudança qualitativa em um produto existente (ex. Smartphone); ii) a inovação de um processo que seja novidade para uma indústria (ex. comida à quilo); iii) a abertura de um novo mercado (ex. café gourmet); iv) o desenvolvimento de novas fontes de suprimento de matéria-prima ou outros insumos 
(ex. medicamento para convalescentes que se tornou energético popular na Inglaterra); ou v) mudanças na organização industrial ou em seu paradigma (ex. produção em massa de carros por Henry Ford).

Outra dimensão necessária para classificar a inovação diz respeito ao seu grau de novidade, ou seja, o quanto o produto existente é novo no mercado ou na sociedade. As inovações ditas radicais são aquelas trazidas por produtos ou serviços antes inexistentes no mercado e que provocam grandes mudanças no mundo, nos mercados e na sociedade. Um exemplo de inovação radical é o advento da WWW, o surgimento dos telefones celulares, a criação das máquinas fotográficas digitais. $\mathrm{O}$ desenvolvimento de inovações radicais envolve muitos riscos, e em alguns casos, pode-se nem sequer ter total controle sobre o que se está produzindo e o efeito que causará. $\mathrm{Na}$ outra ponta deste espectro relacionado à novidade, estão as inovações incrementais, que são aquelas inovações que preenchem continuamente o processo de mudança, quer seja em uma organização, região, país ou no mundo. Por exemplo, as constantes alterações nos dispositivos celulares, são inovações incrementais. Inovações radicais tendem a ter alto impacto e, consequentemente, possuem potencial de resultados comerciais muito altos. Já as inovações incrementais, partem de algo já conhecido que se deseja aprimorar, possuem menor risco em seu desenvolvimento, e embora também apresentem resultados esperados positivos, são em, em geral, em escala menor.

\subsubsection{Inovação Tecnológica}

Dentre os diversos contextos onde as iniciativas de inovação surgem no mundo, o conceito de inovação tecnológica é um dos que mais têm sido explorados. Em grande parte, pelo fato de que a tecnologia, em seu sentido mais amplo, há séculos tem sido o principal agente de avanços científicos, econômicos e sociais.

O Manual de Oslo (2006) define o conceito de Inovações Tecnológicas em Produtos e Processos (TPP) como: “(...) implantações de produtos e processos tecnologicamente novos e substanciais melhorias tecnológicas em produtos e processos. Uma inovação TPP é considerada implantada se tiver sido introduzida no mercado (inovação de produto) ou usada no processo de produção (inovação de processo). Uma inovação TPP envolve uma série de atividades científicas, tecnológicas, organizacionais, financeiras e comerciais. Uma empresa inovadora em TPP é uma empresa que tenha implantado produtos ou processos tecnologicamente novos ou com substancial melhoria tecnológica durante o periodo em análise." Devemos reparar que o Manual se preocupa em esclarecer que inovação só existe quando implantada e que deve ser distinguida em relação à sua natureza: inovações de produtos (e aqui incluem-se bens ou serviços) ou processos. Além disso, precisa apresentar características novas ou melhorias substanciais, ou seja, devem caracterizar seu grau de novidade, conforme discutido anteriormente.

Então, produtos tecnologicamente novos são aqueles cujas características tecnológicas ou usos pretendidos diferem daqueles dos produtos produzidos anteriormente. Isto pode envolver tanto tecnologias radicalmente novas, como se basear na combinação de tecnologias existentes em novos usos ou mesmo derivadas do uso de novo conhecimento. Produtos tecnologicamente aprimorados são produtos existentes cujo desempenho tenha sido significativamente aprimorado ou elevado. Isto inclui tanto um produto simples aprimorado (em termos de melhor desempenho ou menor custo) através de componentes ou materiais de desempenho melhor; como um produto complexo 
que consista em vários subsistemas técnicos integrados pode ser aprimorado através de modificações parciais em um dos seus subsistemas.

Inovações tecnológicas de processos, por sua vez, incluem a adoção de métodos de produção novos ou significativamente melhorados, incluindo métodos de entrega dos produtos. Estes métodos podem envolver: mudanças em equipamentos, mudanças na organização da produção, combinação das mudanças anteriores ou podem derivar do uso de novo conhecimento. Os métodos adotados podem ter por objetivo produzir ou entregar produtos tecnologicamente novos ou aprimorados, que não possam ser produzidos ou entregues com os métodos convencionais de produção e/ou aumentar a produção ou eficiência na entrega de produtos existentes.

O Manual também classifica as inovações tecnológicas de acordo com sua cobertura: i) máxima: algo novo no mundo; ii) intermediária: algo novo em uma região ou país; ou iii) mínima: algo novo na empresa (incluindo também a inovação tecnológica de processo em atividades secundárias da organização). A figura 1.1 resume as características da inovação tecnológica em produtos e processos (TPP) segundo o Manual de Oslo.

\begin{tabular}{|c|c|c|c|c|c|c|}
\hline & \multicolumn{3}{|c|}{ INOVAÇÃO } & \multirow{2}{*}{$\begin{array}{c}\text { NĀO } \\
\text { INOVAÇĀo }\end{array}$} \\
\hline & & & Máxima & Intermediária & Mínima & \\
\hline & & & Novo no mundo & $\begin{array}{l}\text { Novo em uma } \\
\text { regiāo ou pais }\end{array}$ & Novo na empresa & Já na empresa \\
\hline \multirow{6}{*}{$\begin{array}{l}\text { INOVAÇÃO } \\
\text { TPP }\end{array}$} & \multirow{3}{*}{$\begin{array}{l}\text { Tecrologicamente } \\
\text { nowo }\end{array}$} & Produto & & & & \\
\hline & & Processo de produçăo & & & & \multirow{5}{*}{$\begin{array}{c}---- \\
---- \\
-----\end{array}$} \\
\hline & & Processo de entrega & & & & \\
\hline & \multirow{3}{*}{$\begin{array}{l}\text { Significativamente } \\
\text { aprimorado } \\
\text { tecrologicamente }\end{array}$} & Produto & & & & \\
\hline & & Processo de produçāo & & & & \\
\hline & & Processo de entrega & & & & \\
\hline Outras inovaçōes & Novo ou aprimorado & $\begin{array}{c}\text { Puramente } \\
\text { organizacional }\end{array}$ & & & & \\
\hline \multirow{4}{*}{$\begin{array}{l}\text { Năoé } \\
\text { inovação }\end{array}$} & \multirow{4}{*}{$\begin{array}{l}\text { Nenhuma mudança } \\
\text { significativa, sem } \\
\text { novidade ou outras } \\
\text { melhorias criativas }\end{array}$} & Produto & & & & \\
\hline & & Processo de produçāo & & & & \\
\hline & & Processo de entrega & - & - & - & ---- \\
\hline & & $\begin{array}{c}\text { Puramente } \\
\text { organizacional }\end{array}$ & & & & \\
\hline
\end{tabular}

Figura 1.1. Caracterizando a inovação (Manual de Oslo, 2006)

\subsubsection{Processos de Inovação}

Uma vez compreendido o conceito da inovação, se motivados ao seu propósito, surge a pergunta: "como tornar a inovação uma realidade?". Atualmente já são conhecidas condições básicas e atividades que compõem os processos voltados à produção da inovação.

Algo que é reconhecidamente sabido no processo de inovar é que inovação é questão de conhecimento - tanto científico, como tecnológico, como empírico. Para que a inovação surja, é preciso conhecer o que já está posto a respeito da ciência, da 
tecnologia e da experiência que existe dentro do tema que se deseja inovar. Inovar também envolve informação e observação do status quo - o que é hoje - em termos de mercado, sociedade e possibilidades tecnológicas. A partir daí a inovação diz respeito à criatividade e criação de coisas novas - o que pode vir a ser.

Organizações comerciais inovam para captar a atenção de seus mercados com novos produtos ou novas formas de disponibilização de produtos. Organizações públicas ou sem fins lucrativos inovam para competir com os desafios de proverem saúde, educação e segurança por exemplo. Os processos de inovação são importantes principalmente para que as empresas vençam o desafio de utilizar recursos escassos de forma mais eficaz ou de se tornar mais ágil e flexível em resposta a um cenário diverso ou novo. Como há potencial inovador em qualquer empresa (RIES, 2018), há necessidade latente de gerir estes processos, o que nos leva à gestão da inovação.

A gestão da inovação surge na tentativa de minimizar o chamado "dilema do inovador", definido por Christensen (1997), que trata a dificuldade das empresas administrarem simultaneamente aspectos estáveis e sustentáveis de seus negócios e ao mesmo tempo lidar com os aspectos descontinuados e disruptivos da inovação. A inovação está sempre associada ao risco e seu potencial reside em menos controle. Mesmo a inovação incremental, que parte de algo conhecido a ser aprimorado, envolve riscos.

Em linhas gerais, são quatro as principais atividades da gestão da inovação (Figura 1.2): i) Procura - analisar o cenário (interno e externo) à procura de - e processar sinais relevantes sobre - ameaças e oportunidades para mudanças; ii) Seleção - decidir considerar a visão estratégica de como uma empresa pode se desenvolver melhor - sobre a quais desses sinais deve responder; iii) Implementação - traduzir o potencial da ideia inicial em algo novo e a lançar em um mercado interno ou externo. Inclui a aquisição de conhecimento, a execução do projeto, lançamento de produtos e sua sustentabilidade no ambiente/mercado; iv) Aprendizagem - aprender - organizar e gerir conhecimento sobre os processos e resultados obtidos com os projetos de inovação.

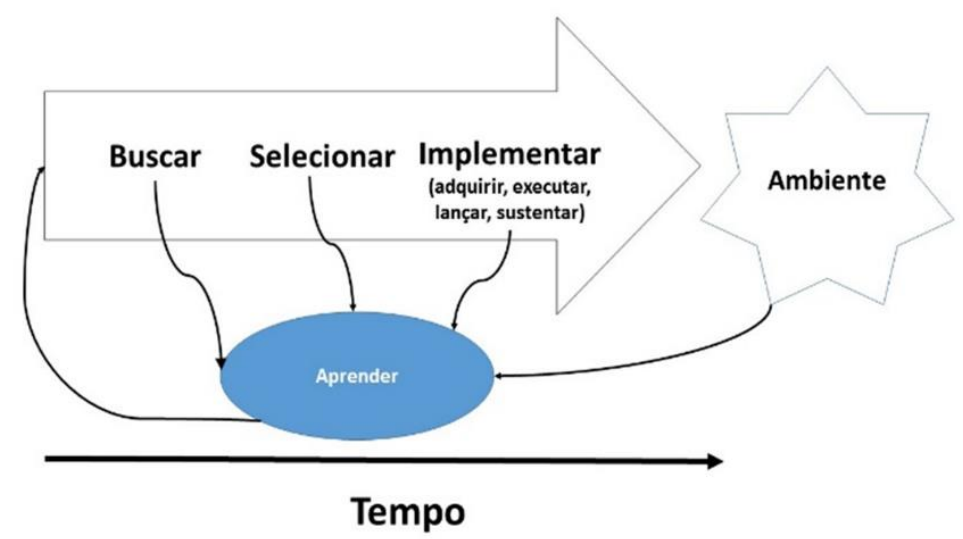

Figura 1.2. Atividades da gestão da inovação (adaptado de Tidd, Bessant \& Pavitt, 2008)

Para lidar com a incerteza do processo de inovação, as organizações traçam estratégias que podem envolver desenvolver estas etapas em visões mais racionais descrever, compreender e analisar o ambiente, determinar um plano de ação e colocá-lo 
em execução - ou visões mais incrementais, baseadas em tentativa e erro - tomar medidas (ou mudanças) deliberadas rumo a um objetivo proposto, medir ou avaliar seus efeitos, e ajustar (se necessário) o objetivo e decidir o próximo passo.

Oliveira (2005, p.29) descreve que "o processo de inovação compreende as etapas de invenção, inovação e difusão. A invenção relaciona-se à criação do novo, podendo ser refletida na publicação de artigos científicos e patentes. No entanto, para que uma invenção se transforme em uma inovação, mesmo que se justifique a viabilidade técnica e econômica do produto ou processo, torna-se necessário o lançamento no mercado e ter sucesso comercial. À medida que uma inovação é introduzida no mercado surgem outras variações, denominadas difusão da inovação, que visam a aproximação dos produtos ou serviços das necessidades do usuário final’'.

Rogers \& Schoemaker (1971 apud Tigre, 2006 p.73) definem difusão como "o processo pelo qual uma inovação é comunicada através de certos canais, através do tempo, entre os membros de um sistema social'. Os processos de inovação e difusão não podem ser totalmente separados, pois, segundo Tigre (2006), em muitos casos a difusão contribui para o processo de inovação, alimentando e direcionando a trajetória da inovação, considerando que a difusão de um produto ou processo no mercado mostra problemas que podem ser corrigidos em novas versões. Esse autor ainda afirma que " $a$ capacidade para aperfeiçoar e adaptar um novo produto ou processo às condições especificas de um setor ou país é fundamental para o sucesso da difusão tecnológica" (Tigre, 2006 p.73).

Portanto, neste processo residem interseções importantes entre a pesquisa científica e o desenvolvimento tecnológico. A pesquisa científica tem como potencial e responsabilidade econômica e social, gerar novas alternativas, ideias e invenções. $\mathrm{O}$ ambiente produtivo, por sua vez, possui capacidade e responsabilidade de introduzir no mercado e na sociedade ideia inovadoras na forma de produtos. No entanto, o conhecimento gerado nestes dois ambientes precisa ser integrado: assim como o ambiente produtivo se beneficia das invenções científicas para a criação de novos produtos, a pesquisa científica pode melhor direcionar suas estratégias, esforços e investimentos quando detém conhecimento sobre os resultados e impactos das inovações de mercado. Por essa razão, temos visto sugestões de meios para que pesquisadores possam integrar às suas pesquisas ferramentas que permitam um contato com o conhecimento tecnológico disponível (Araujo et. al. 2018)(Nunes e Pinheiro-Machado, 2017), entre elas, a prospecção tecnológica.

\subsection{Prospecção Tecnológica}

A prospecção tecnológica é o termo utilizado nos estudos que têm por finalidade antecipar e entender as potencialidades, evolução, características e efeitos das mudanças tecnológicas, particularmente a sua invenção, inovação, adoção e uso (Coates et al., 2001)(Tigre, 2006 apud Teixeira, 2013 p. 16). Nessa perspectiva, a prospecção tecnológica é parte integrante do processo de gestão da inovação, visando agregar a previsão de possíveis impactos (sociais, econômicos, ambientais, institucionais) de uma determinada tecnologia.

A prospecção é uma atividade multicritério, sujeita a incertezas e com algum grau de subjetividade, exigindo a aplicação de métodos sofisticados. Conforme Abreu (2017), os métodos de prospecção possuem três sistemas de classificação a saber: quanto a 
natureza, a abordagem e a fonte de conhecimento. Quanto a natureza, podem ser classificados em métodos qualitativos, quantitativos ou semi-quantitativos cujos exemplos são apresentados na Tabela 1.1.

Tabela 1.1 - Métodos de prospecção tecnológica (extraído de Abreu, 2017)

\begin{tabular}{|c|c|}
\hline \multicolumn{2}{|r|}{ Métodos de Prospecção qualitativos } \\
\hline Workshop de cenário & $\begin{array}{l}\text { Atividade em grupo com programação dedicada à confecção de cenários } \\
\text { futuros, possui duração pré-estabelecida reunindo grupos heterogêneos para } \\
\text { refletir sobre os objetivos, alvos e ações do processo de prospecção. }\end{array}$ \\
\hline Entrevista & $\begin{array}{l}\text { Atividade que reúne pelo menos dois participantes na qual é realizada uma } \\
\text { consulta para captar as avaliações e o conhecimento tácito dos entrevistados } \\
\text { sobre o tema. A entrevista pode ser estruturada (objetiva) e parcialmente } \\
\text { estruturada (objetiva e discursiva). }\end{array}$ \\
\hline $\begin{array}{l}\text { Brainstorming/ } \\
\text { tempestade de ideias }\end{array}$ & $\begin{array}{l}\text { Atividade em grupo e interativa na qual as ideias dos participantes (propostas, } \\
\text { reflexões, opiniões) sobre um tema são expostas, sem prévia censura, e, } \\
\text { depois discutidas em profundidade. As propostas relevantes são classificadas } \\
\text { quanto ao grau de pertinência ao assunto. }\end{array}$ \\
\hline $\begin{array}{l}\text { Matriz de forças, } \\
\text { oportunidades, } \\
\text { fraquezas e ameaças } \\
\text { (FOFA) }\end{array}$ & $\begin{array}{l}\text { Atividade opcionalmente em grupo que consiste na elaboração de matrizes } \\
\text { onde são especificadas as dimensões interna (forças e fraquezas) e externa } \\
\text { (limites e oportunidades) sobre um tema. Este método permite explorar } \\
\text { estratégias, identificar recursos e capacidades. }\end{array}$ \\
\hline \multicolumn{2}{|r|}{ Métodos de Prospecção quantitativos } \\
\hline $\begin{array}{l}\text { Extrapolação de } \\
\text { tendências/análise de } \\
\text { impacto }\end{array}$ & $\begin{array}{l}\text { Consiste em extrapolar tendências passadas e resultados presentes de } \\
\text { indicadores de um tema num horizonte de tempo futuro (curto, médio, longo), } \\
\text { atribuir probabilidade de ocorrência (provável, possível, especulativo) e } \\
\text { consequência (positiva, neutra, negativa). }\end{array}$ \\
\hline Bibliometria & $\begin{array}{l}\text { Compilação e análise quantitativa e estatística de informações de publicações } \\
\text { (livros, jornais, revistas e demais fontes) para capturar e informar o } \\
\text { conhecimento existente sobre um tema, as tendências e questões emergentes. }\end{array}$ \\
\hline $\begin{array}{l}\text { Mineração de dados em } \\
\text { ciência e tecnologia }\end{array}$ & $\begin{array}{l}\text { Semelhante à bibliometria, mas dela diferenciando-se pelo foco exclusivo nas } \\
\text { informações em ciência e tecnologia (patentes e publicações especializadas). }\end{array}$ \\
\hline \multicolumn{2}{|r|}{ Métodos de Prospecção semi-quantitativos } \\
\hline Delphi & $\begin{array}{l}\text { Atividade em grupo interativa que envolve sucessivas consultas aos } \\
\text { participantes sobre um tema/questão do processo prospectivo. A cada rodada, } \\
\text { o grupo é reduzido, as opiniões são consolidadas e apresentadas aos } \\
\text { remanescentes para então, aplicar-se nova consulta em cada etapa. Ao final, } \\
\text { espera-se atingir o consenso ou a construção de opinião alternativa sobre o } \\
\text { tema e minimizar a possibilidade das influências de poder/conhecimento } \\
\text { entre os participantes sobre o resultado obtido. }\end{array}$ \\
\hline $\begin{array}{l}\text { Matriz de impacto } \\
\text { cruzado/análise } \\
\text { estrutural }\end{array}$ & $\begin{array}{l}\text { Consiste em elaborar matrizes para avaliar simultaneamente mais de uma } \\
\text { variável no contexto do tema/questão do processo prospectivo. Estas } \\
\text { variáveis são distribuídas em linhas e colunas onde a célula formada pela } \\
\text { interseção da linha com a coluna é preenchida com métricas que reflitam o } \\
\text { impacto desta combinação à luz do tema (em geral na forma percentual). }\end{array}$ \\
\hline $\begin{array}{l}\text { Roadmapping/mapa } \\
\text { direcional }\end{array}$ & $\begin{array}{l}\text { Consiste em uma versão do backasting }{ }^{l} \text { caracterizada pelo uso de linha } \\
\text { temporal na qual a influência dos principais atores, aspectos regulatórios, } \\
\text { tecnologias e mercado são avaliadas em mapas lógicos com a finalidade de } \\
\text { comunicação, troca e desenvolvimento de visão coletiva. }\end{array}$ \\
\hline
\end{tabular}

${ }^{1}$ Backasting: atividade, opcionalmente em grupo, que consiste em estabelecer uma imagem do futuro e delinear uma trajetória de como alcançá-lo com foco na identificação de estratégias e políticas adequadas (Abreu, 2017) 
Quanto a abordagem, os métodos podem ser classificados em exploratório, normativo, evolucionário ou revolucionário. No exploratório, as opções do futuro são construídas pelos insumos informacionais gerados durante o processo de prospecção, enquanto que na normativa toda a informação é customizada tendo em vista o alcance do futuro pré-estabelecido. Por outra vertente, os estudos evolucionário e revolucionário buscam o aprimoramento do tema/questão no contexto dinâmico (Abreu, 2017). Tais tipos de estudos não são excludentes, pois decorrem do aprendizado construído durante a avaliação do processo de prospecção.

Por fim, quanto a fonte de conhecimento os métodos prospectivos são classificados como orientados para: (i) criatividade: onde predomina a imaginação e pensamento intuitivo como, por exemplo, genius forecasting, backasting e ensaios; (ii), experiência: são aqueles dependentes do conhecimento acumulado dos participantes em relação ao tema/questão do processo prospectivo, como, por exemplo, a análise morfológica e avaliação de tecnologias-chave/críticas; (iii) interação: predominam as atividades de grupo que demandam debate ou articulação entre os participantes como, por exemplo, workshops, painel de cidadãos e análise de stakeholders; e (iv) evidência: combinam as fontes de informação baseadas em parâmetros e indicadores estatísticos, conjugadas com as suas respectivas análises, tendo por lema o subsídio à ação informada dos participantes como, por exemplo, a bibliometria, análise de tendências e das informações de CT (Popper, 2008b apud Abreu, 2017).

\subsubsection{Fontes de Informação Tecnológica}

Existem diversos tipos de informação de natureza tecnológica para a composição de roadmaps. Alvares (1997 apud Jannuzzi \& Montalli, 1999) define informação tecnológica como "todo tipo de conhecimento sobre tecnologia de fabricação, de projeto $e$ de gestão que favoreça a melhoria contínua da qualidade e a inovação no setor produtivo". Battaglia (1999 p.208), a partir de estudos de Stollenwerk (1997 apud Battaglia, 1999) apresenta-os por tipologia e complexidade, apresentados a seguir:

i) Informação científica: circula principalmente no meio acadêmico e é necessária à fase de laboratório da pesquisa básica, aplicada ou do desenvolvimento experimental. Ela corresponde à informação contida em revistas científicas, teses, relatórios internos e anais de congressos.

ii) Informação técnica: é necessária na fase que antecede a concretização de decisões. Trata-se do "estado-da-arte" e caracteriza-se sobretudo pelas informações contidas nas patentes.

iii) Informação tecnológica: é a informação que retrata a realização prática do desenvolvimento, o que significa colocar em operação as unidades industriais, mediante construção de protótipos, de unidades piloto. Complementa as informações contidas nas patentes, caracterizando o "saber fazer" o know how.

iv) Informação técnico-econômica: refere-se aos dados macroeconômicos apontados pelos países em forma de resultados, estratégias, cooperação, parcerias, produtos, unidades de produção e mercados, como por exemplo, relatórios anuais e publicações das empresas.

v) Informações do tipo complementar: dizem respeito aos aspectos regulamentares e normativos, jurídicos, de segurança e meio ambiente, os quais devem ser considerados na fase de concepção do projeto de pesquisa. Ex. normas. 
Mesmo que esta informação esteja amplamente disponível, a sua plena utilização dependerá da capacidade de aprendizagem e dos conhecimentos já assimilados por aqueles que terão acesso a essas informações, sejam os usuários pessoas físicas, sejam instituições. Desta forma, a capacidade de reunir, organizar, analisar e produzir conhecimento proporcionando mudanças a partir do acesso às informações torna-se um diferencial competitivo (Lastres \& Ferraz, 1999 apud Souza et al., 2007).

O monitoramento dessas informações oferece vantagens tais como (Jannuzzi et al., 2005 apud Souza et al., 2007): (i) evitar duplicação de esforços e investimentos em P\&D; (ii) identificar novas ideias e soluções técnicas, produtos e processos, estimulando o desenvolvimento tecnológico e a geração de inovações; (iii) identificar o estado-da-arte e o estágio em que se encontra uma determinada tecnologia; (iv) identificar nichos de mercado e tendências relativas a uma nova tecnologia ou produto ainda em fase embrionária; (v) identificar alternativas tecnológicas para um determinado problema; (vi) ter acesso e avaliar uma tecnologia específica bem como identificar possíveis licenciadores; (vii) localizar fontes de know how em um segmento tecnológico específico ou em um determinado país; (viii) identificar pesquisadores, grupos de pesquisa e instituições que tenham interesse em determinada tecnologia de modo a possibilitar futuras parcerias; (ix) identificar a existência de direitos de propriedade intelectual evitando cometer infrações; (x) avaliar o potencial de tecnologias e produtos resultantes de esforço próprio com vistas a garantir os direitos de propriedade intelectual; e (xi) monitorar a atividade de competidores.

Dentre as fontes de informação tecnológica, neste capítulo o foco será explorar o uso de patentes e de artigos científicos, haja vista que os últimos são os mais usualmente utilizados pela comunidade acadêmica no entendimento do estado da arte em um domínio, e os primeiros - as patentes - são o foco principal de registro de propriedade intelectual no Brasil e no mundo (Araújo et al. 2018)(Araújo \& Chueri, 2018).

Cabe destacar ainda que, embora não seja explorado nesse estudo, o registro de programa de computador (software) é uma fonte de informação tecnológica relevante na área de SI uma vez que permite identificar o campo de aplicação desses programas que estão sendo desenvolvidos. Tal registro é protegido pela lei do direito autoral, o que garante a exclusividade na produção, uso e comercialização do programa de Computador registrado (Russo et al., 2012 apud Guimaraes et al, 2018).

\subsubsection{Patentes}

As patentes são uma das formas mais antigas de proteção à propriedade intelectual ${ }^{2} \mathrm{e}$ possibilitam verificar a proteção dos progressos científicos realizados nas mais diferentes áreas tecnológicas (Lima, 2005). A Figura 1.3 ilustra a Propriedade Intelectual e suas divisões.

\footnotetext{
${ }^{2}$ Segundo WIPO (2005 apud LIMA, 2005), propriedade intelectual relaciona-se a criações humanas, como, trabalhos literários e artísticos, símbolos, nomes, imagens e desenhos usados no comércio. É dividida em duas categorias: (i) propriedade industrial que inclui patentes, marcas, desenhos industriais e indicações geográficas; e (ii) direitos autorais que inclui trabalhos literários como romances, peças, filmes, livros, músicas.
} 


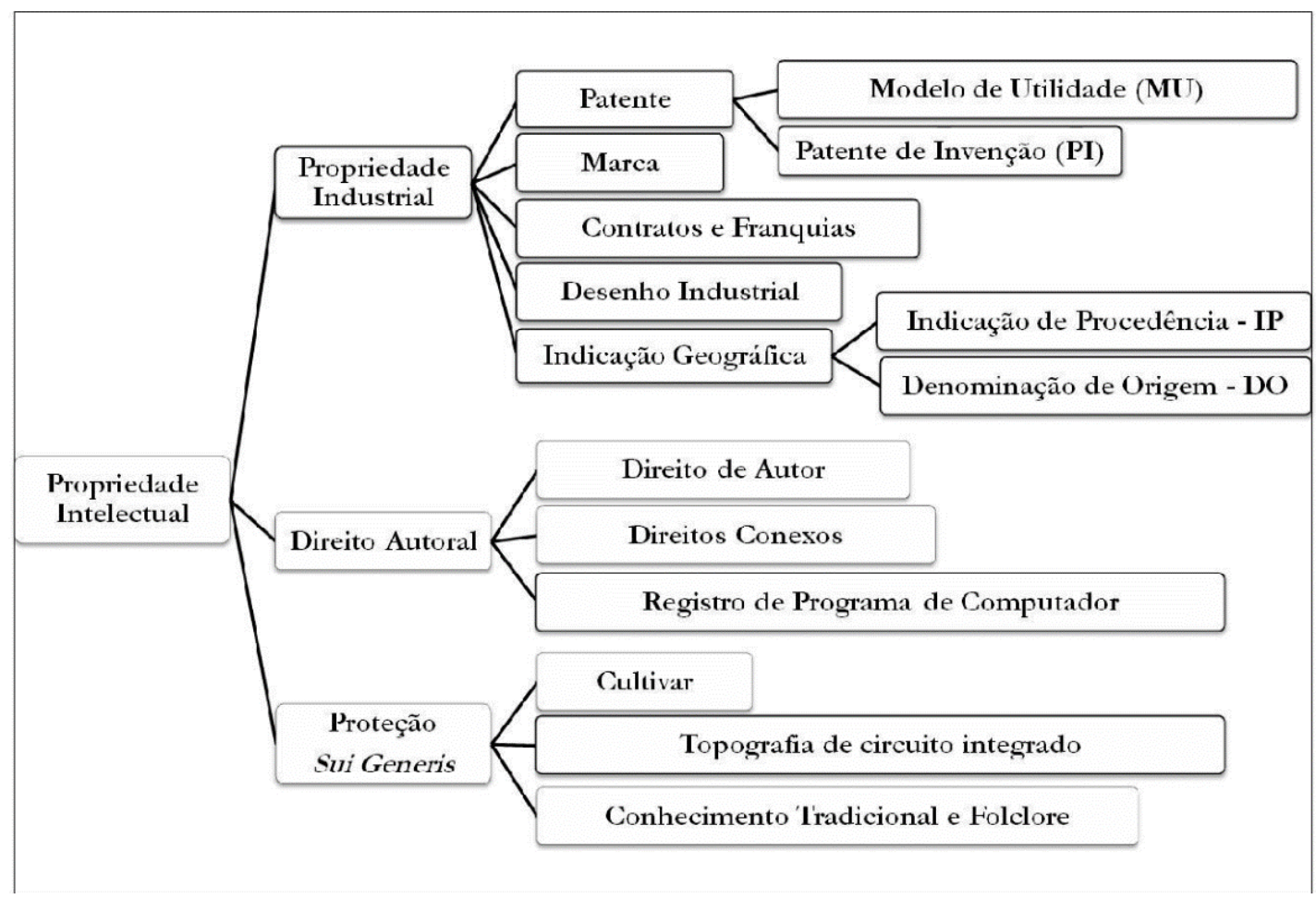

Figura 1.3. A Propriedade Intelectual e suas divisões. (Nunes e Pinheiro-Machado, 2017)

As patentes são ativos intangíveis que protegem criações suscetíveis de serem convertidas em bens materiais ou ativos tangíveis industrializáveis uma vez que conferem ao titular o direito de impedir terceiro, sem o seu consentimento, de produzir, usar, colocar à venda, vender ou importar com esse propósito, o produto objeto de patente e o processo ou produto obtido diretamente por processo patenteado (LPI, 1996). Em contrapartida, o inventor se obriga a revelar detalhadamente todo o conteúdo técnico da matéria protegida pela patente (Januzzi et al., 2007). As patentes são classificadas como Patentes de Invenção (PI) - descrevem uma tecnologia que solução um problema técnico - e Modelos de Utilidade (MU) - descrevem uma melhoria funcional na forma ou estrutura de um objeto.

Pode-se afirmar que a patente cumpre três objetivos (Januzzi et al., 2007; Lima 2005): i) proteger os titulares da patente contra imitações de modo que possam recuperar os investimentos realizados no desenvolvimento daquela invenção; ii) garantir o retorno dos investimentos realizados pela organização através da comercialização dos produtos e ainda pelo pagamento de royalties; e iii) estimular o desenvolvimento tecnológico a partir da revelação à sociedade do conteúdo protegido disseminando conhecimento $\mathrm{e}$ informações tecnológicas.

De acordo com Alencar (2016), a patente é um título de propriedade temporária sobre invenção ou modelo de utilidade, outorgado pelo Estado aos inventores ou autores ou outras pessoas físicas ou jurídicas detentoras de direitos sobre a criação para fazer uso comercial de suas invenções. Quando o título já foi concedido, é chamada de patente concedida (issued patent); quando ainda está na fase de análise pelo órgão responsável é chamado de pedido de patente (applied patent).

Para haver a concessão de uma patente é necessário o atendimento de cinco requisitos (Araújo \& Chueri, 2018)(Lima, 2005): (i) novidade, quando a invenção não se encontra compreendida no estado da técnica, ou seja, não tenha se tornado acessível ao público antes da data de depósito do pedido de patente, por descrição escrita ou oral, por 
uso ou qualquer outro meio, no mundo; (ii) atividade inventiva (PI)/ato inventivo, quando a invenção é dotada de atividade inventiva sempre que, para um técnico no assunto, não decorra de maneira evidente ou óbvia do Estado da Técnica; um modelo de utilidade é dotado de ato inventivo sempre que, para um técnico no assunto, não decorra de maneira comum ou vulgar no Estado da Técnica; (iii) aplicação industrial, o que significa que a invenção é suscetível de aplicação industrial quando possa ser utilizada ou produzida em qualquer tipo de indústria; (iv) melhoria funcional, quando a introdução em objeto de uma forma ou disposição acarrete comodidade ou praticidade ou eficiência à sua utilização e/ou obtenção; e (v) suficiência descritiva, a invenção deve ser descrita de forma clara e completa, de modo a permitir sua reprodução por um técnico no assunto.

Outro ponto a destacar é a existência de organizações que possuem políticas particulares de patenteamento, podendo optar por proteger suas invenções e inovações através de segredo industrial. Aqui, cabe ainda destacar que nem toda patente se transforma em inovação ${ }^{3}$, conforme mencionado na fundamentação teórica.

Patentes têm se mostrado uma fonte de informação tecnológica relevante para aqueles que buscam a manutenção da competitividade num mercado globalizado e constitui-se o primeiro meio de divulgação de inovações para as indústrias. $\mathrm{O}$ uso da proteção patentária como fonte de informação tecnológica, e também como indicador de desenvolvimento tecnológico, apresenta algumas desvantagens que podem justificar a sua não utilização em larga escala em países como o Brasil, tais como: o desconhecimento do profissional da informação sobre as patentes; o elevado custo dos trâmites para a obtenção de uma patente; em áreas de rápida evolução tecnológica há o risco de obsolescência devido ao período de sigilo; áreas como tecnologia da informação, produtos farmacêuticos e químicos podem preferir proteger seus inventos via segredo industrial, dentre outros (França, 1997).

Segundo Barbosa \& Macedo (2000 apud PERES, 2005) o sistema de informações tecnológicas contidas em documentos de patente apresenta diversas vantagens para os usuários que são apresentadas na Tabela 1.2:

Tabela 1.2 - Vantagens apresentadas nas patentes (extraídos de Peres, 2005)

\begin{tabular}{|l|l|}
\hline $\begin{array}{l}\text { Tecnologia por } \\
\text { excelência }\end{array}$ & $\begin{array}{l}\text { É o único sistema de informação configurado para a finalidade de armazenar } \\
\text { conhecimentos tecnológicos, ou seja, destinados à produção de mercadorias. A } \\
\text { informação patentária tem a finalidade de divulgar informação técnico-produtiva. }\end{array}$ \\
\hline $\begin{array}{l}\text { Classificação } \\
\text { tecnológica }\end{array}$ & $\begin{array}{l}\text { A Classificação Internacional de Patentes (CIP) é o único sistema de classificação } \\
\text { configurado para ordenar as informações técnicas de produção, restrita e } \\
\text { especializada para atender à área da produção econômica. }\end{array}$ \\
\hline Complementaridade & $\begin{array}{l}\text { Os documentos de patente geralmente têm um levantamento do estado da técnica } \\
\text { até o momento da invenção que descreve, informando as patentes anteriores, } \\
\text { publicações técnicas, nomes dos inventores, empresas titulares, palavras-chave. } \\
\text { As informações patentárias podem esclarecer e complementar artigos divulgados } \\
\text { pelo inventor, proporcionando visão geral e ampla da invenção, o que nem } \\
\text { sempre é feito nos artigos técnicos. }\end{array}$ \\
\hline Originalidade & $\begin{array}{l}\text { A invenção, para se patenteável, deve ter novidade. Sua divulgação pública } \\
\text { original deve ser obrigatoriamente por meio da publicação do documento de } \\
\text { patente. }\end{array}$ \\
\hline
\end{tabular}

\footnotetext{
${ }^{3}$ Segundo Barbieri (2005 p. 59) "nem toda invenção se transforma em inovação, pois esta só se efetiva se o mercado aceitá-la".
} 


\begin{tabular}{|l|l|}
\hline Atualidade & $\begin{array}{l}\text { Os criadores do conhecimento técnico-produtivo têm por política patentear } \\
\text { prontamente os resultados de suas pesquisas e desenvolvimento ou de soluções } \\
\text { técnicas realizadas por ocasião do processo de produção. A documentação de } \\
\text { patente contém a mais atualizada informação tecnológica existente, facilitando a } \\
\text { promoção de invenções com menor dispêndio de tempo e recursos humanos e } \\
\text { financeiros. }\end{array}$ \\
\hline $\begin{array}{l}\text { Competitividade } \\
\text { técnica e econômica }\end{array}$ & $\begin{array}{l}\text { A patente permite auferir uma prospectiva dos ramos de atividade para os quais } \\
\text { caminha a indústria, a agricultura etc. É possível detectar-se os caminhos de } \\
\text { pesquisa de empresas concorrentes, o estágio de avanço. }\end{array}$ \\
\hline $\begin{array}{l}\text { Padronização e } \\
\text { Uniformidade }\end{array}$ & $\begin{array}{l}\text { Os documentos provenientes dos mais distintos países apresentam diferenças } \\
\text { relativamente pequenas em relação à uniformidade e à padronização. }\end{array}$ \\
\hline $\begin{array}{l}\text { Quebra da barreira } \\
\text { lingüística }\end{array}$ & $\begin{array}{l}\text { A maioria das patentes com relevância técnica e/ou econômica pode também ser } \\
\text { encontrada em outras línguas, dada a provável existência da denominada família } \\
\text { de patentes. Em muitos casos é possível, pelo menos, a obtenção do resumo em } \\
\text { língua inglesa. }\end{array}$ \\
\hline
\end{tabular}

Na Tabela 1.2 destaca-se a questão da padronização e uniformidade da informação encontrada nas patentes. O conteúdo informacional das patentes toma a forma de referência bibliográfica, altamente padronizada, com ferramenta de recuperação própria e utilizada por todos os países signatários da Organização Mundial da Propriedade Industrial (OMPI), que é a Classificação Internacional de Patentes (Battaglia, 1999).

Para a construção de roadmaps, Borshiver \& Silva (2016) sugerem que a patente concedida teoricamente demostre "um grau avançado do desenvolvimento de tecnologias pelo detentor da patente, pois, se já houve proteção, o objetivo está mais próximo de sua fase comercial". Ainda segundo as autoras, o pedido de patente também demostra grau avançado de desenvolvimento da tecnologia, mas "como a proteção está em análise, possivelmente o objeto está mais distante de sua fase comercial".

O conhecimento disponível nas patentes ainda é pouco usado pela comunidade acadêmica em suas pesquisas. Tal fato pode estar associado, dentre outros fatores, ao desconhecimento da linguagem particular utilizada na redação de pedidos de patente. Os termos encontrados em tais documentos possuem significados muito próprios, tornandose não facilmente compreendidos por aqueles não familiarizados com essa terminologia (Liebesny, 1972 apud Jannuzzi \& Gomes, 2008).

\subsection{Estrutura do documento de patente}

A estrutura de um documento de patente consiste de: folha de rosto; relatório descritivo; desenhos (se necessário); reivindicações; e resumo (Figura 1.4). A folha de rosto apresenta dados de identificação: título da patente e natureza do documento, data de depósito do pedido, nome do inventor e do titular da patente, país de prioridade, países de depósito e países designados, códigos da Classificação Internacional de Patentes $(\mathrm{CIP})^{4}$; o relatório descritivo descreve a invenção em detalhes suficientes para que qualquer pessoa habilitada neste campo do conhecimento possa reconstruir a invenção; desenhos (se necessário) para melhor mostrar detalhes técnicos da invenção; as reivindicações determinam o alcance da proteção que se deseja; e o resumo, descreve brevemente a invenção (Januzzi et al., 2007; Lima, 2005).

\footnotetext{
${ }^{4}$ http://www.inpi.gov.br/menu-servicos/patente/classificacao-de-patentes
} 


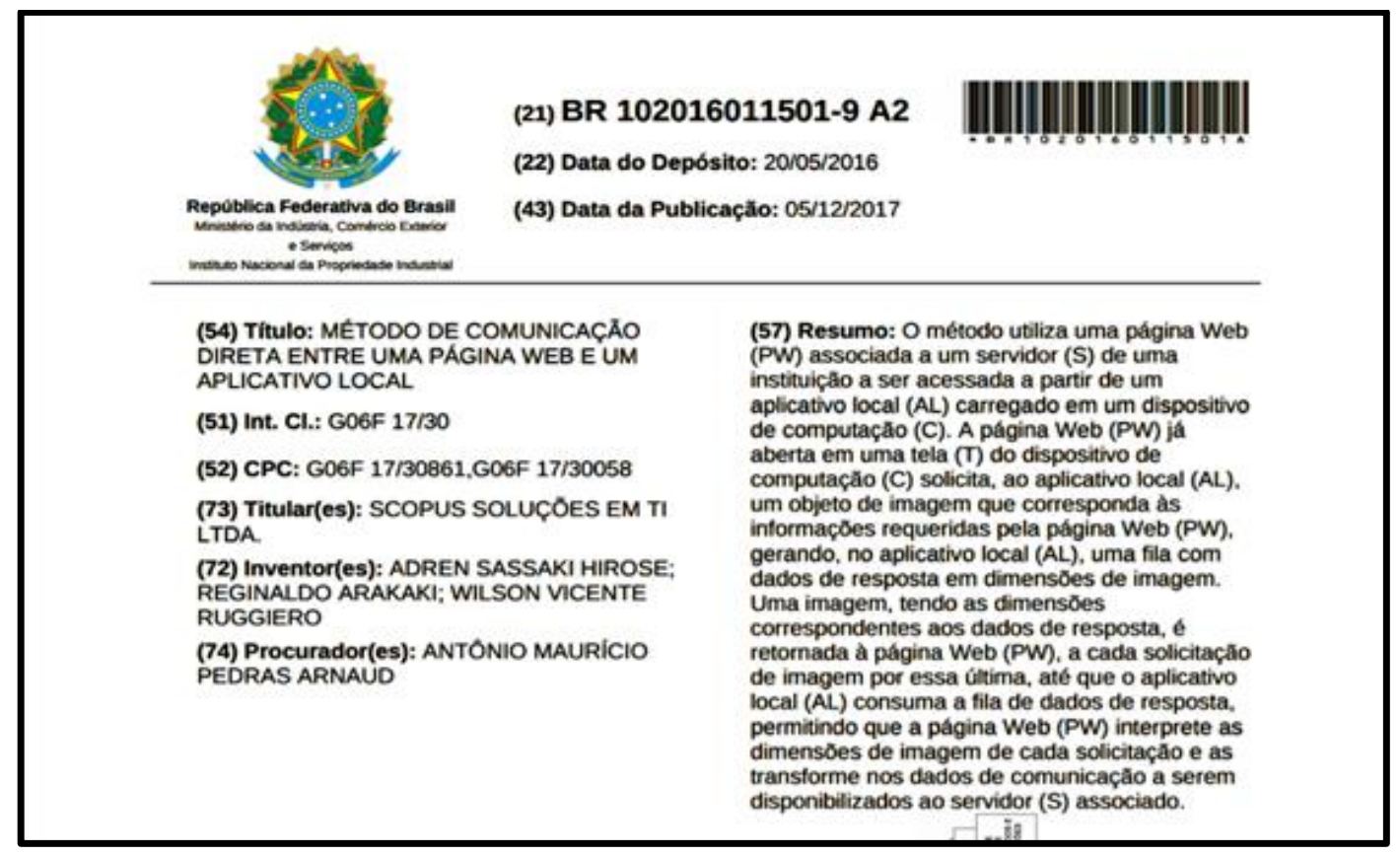

Figura 1.4. Folha de rosto de uma patente. Fonte: INPI

A CIP é um sistema de classificação configurado e criado com o objetivo de recuperar informações contidas em documentos de patentes de forma rápida e eficaz (Peres, 2005). A CIP segue uma estrutura hierárquica na qual toda a área da tecnologia é dividida em seções, classes, subclasses e grupos. Tal sistema é de fundamental importância na recuperação de documentos de patentes em buscas para determinação da novidade de uma invenção ou do estado da arte em uma área da tecnologia específica (WIPO, 2019).

A CIP é periodicamente revista a fim de que indexações mais específicas possam acontecer à medida que novas tecnologias sejam criadas, facilitando a recuperação da informação pelos usuários do sistema. Atualmente se encontra dividida em oito seções que organizam diferentes áreas da tecnologia (WIPO, 2019): Seção A (Necessidades Humanas); Seção B (Operações de Processamento; Transporte); Seção C (Química e Metalurgia); Seção D (Têxteis e Papel); Seção E (Construções Fixas); Seção F (Eng. Mecânica/Iluminação/Aquecimento); Seção G (Física); e Seção H (Eletricidade).

Como exemplo, a classificação da patente apresentada abaixo (Figura 1.4) - G06F 17/30 - pode ser entendida conforme apresentado abaixo:

G - Seção G - Física

G06 - Cômputo; Cálculo; Contagem

G06F - Processamento elétrico de dados digitais

G06F 17/00 - Equipamentos ou métodos de computação digital ou de processamento de dados, especialmente adaptados para funções específicas

G06F 17/30 - Recuperação das informações; respectivas estruturas de banco de dados 


\subsection{Bases de Informação sobre Propriedade Intelectual}

Jagher (2017), Nunes (2014) e Nunes e Pinheiro-Machado (2017) indicam uma lista de sites e bases de consultas públicas e privadas onde são disponibilizadas informações sobre propriedade intelectual. Estas bases podem conter informações restritas a um país ou ao mundo inteiro. Variam em formas de acesso, disponibilidade de formato dos itens e procedimentos de busca, conforme apresentado na Tabela 1.3.

Tabela 1.3. Bases de Informação sobre Propriedade Intelectual (Nunes e Pinheiro-Machado, 2017)

\begin{tabular}{|l|l|}
\hline INPI (www.inpi.gov.br) & $\begin{array}{l}\text { Disponibiliza documentos nacionais e estrangeiros em todas as áreas } \\
\text { de conhecimento, via busca online. Base principal de patentes } \\
\text { brasileiras. }\end{array}$ \\
\hline $\begin{array}{l}\text { PATENTSCOPE } \\
\text { www.wipo.int/patentscope/en) }\end{array}$ & $\begin{array}{l}\text { Base de patentes da OMPI que reúne patentes depositadas através do } \\
\text { PCT (Patent Cooperation Treaty), oriundas de diversos escritórios de } \\
\text { patentes do mundo. }\end{array}$ \\
\hline $\begin{array}{l}\text { Derwent World Patent Index } \\
\text { (DWPI) }\end{array}$ & $\begin{array}{l}\text { Criada e mantida pela Thomson Reuters, tem cobertura de diversos } \\
\text { escritórios de patentes no mundo. Disponibilizada à comunidade } \\
\text { brasileira de pesquisa através da Capes e Fapesp, acesso por } \\
\text { computadores internos das universidades. }\end{array}$ \\
\hline $\begin{array}{l}\text { Esp@cenet (ep.espacenet.com }) \\
\text { Base do Escritório Europeu de Patentes (EPO), contendo patentes do } \\
\text { mundo todo. }\end{array}$ \\
\hline $\begin{array}{l}\text { GSPTO (www.uspto.gov) } \\
\text { (www.google.com/patents) }\end{array}$ & Base de patentes norte-americanas. \\
\hline pearch & $\begin{array}{l}\text { Foco em patentes norte americanas, atualmente permite a busca em } \\
\text { bases de patentes públicas de todo o mundo. }\end{array}$ \\
\hline
\end{tabular}

\subsubsection{Artigos Científicos}

Os artigos de científicos podem ser definidos como "trabalhos técnico-científicos, escritos por um ou mais autores, com a finalidade de divulgar a sintese analítica de estudos e resultados de pesquisas" (UFPR, 2000 apud Weiss, s/d). Por meio de sua divulgação, a pesquisa é formalizada, o conhecimento torna-se público e é promovida a comunicação entre os pesquisadores.

Para Merton (1957 apud Macias-Chapula, 1998) a publicação dos resultados de suas pesquisas é um compromisso que os cientistas são obrigados a cumprir uma vez que o avanço do conhecimento produzido pelos pesquisadores tem que ser transformado em informação acessível para a comunidade científica como um todo. Assim, a pesquisa é desenvolvida num contexto de troca entre esta comunidade. A publicação dos resultados de pesquisa tem três objetivos: divulgar descobertas científicas, salvaguardar a propriedade intelectual (direitos autorais) e alcançar o reconhecimento pelos pares (Okubo, 1997 apud Macias-Chapula, 1998).

Os artigos podem ser, assim como os documentos de patente, uma importante fonte de informação tecnológica. No entanto, diferente das patentes, "demostram um grau inicial do desenvolvimento da tecnologia, uma vez que se encontra ainda em fase de estudo acadêmico" (Borschiver \& Silva, 2016). 
Segundo Macias-Chapula (1998), a Organização para Cooperação e Desenvolvimento Econômico (OCDE) fez referência à bibliometria - que estuda os artigos, livros, autores dentre outros - como uma ferramenta que permite observar o estado da ciência e da tecnologia através da produção da literatura científica como um todo, em um determinado nível de especialização. A análise dos bancos de dados contendo artigos oferece uma gama de informações sobre a orientação e a dinâmica científica de um país, bem como sobre sua participação na ciência e na tecnologia mundial. Análises cooperativas tornam possível identificar redes científicas e revelar os elos entre países, instituições e pesquisadores, assim como permitem conhecer o impacto dos principais programas e organizações (Macias-Chapula, 1998).

As bases nacionais e internacionais de artigos científicos, na área de Computação e SI - Scopus, ACM, Compendex, entre outras - são bastante conhecidas da comunidade de pesquisa, e optamos por não entrarmos em detalhes a respeito delas neste capítulo.

\subsection{Technology Roadmapping (TRM)}

A literatura tem apresentado o termo technology roadmap em diferentes maneiras, tais como technology roadmap, technology roadmap ou somente roadmap, ou ainda na forma abreviada TRM (Lee \& Park, 2005). Usualmente, a expressão road map refere-se a um layout de caminhos ou rotas que existem ou podem existir em um espaço geográfico particular para ajudar os viajantes no planejamento da viagem a fim de atingir um destino específico (Schaller, 2004).

Tal definição auxilia a compreender o método technology roadmapping (TRM), que consiste em representar graficamente a rota de evolução das tecnologias, produtos e mercados existentes (hoje) e que será construída (futuro), auxiliando os líderes (viajantes) de uma organização no planejamento e alinhamento das ações de desenvolvimento com as metas do negócio (destino) (Mattos Neto, 2005). De uma forma geral, a definição do método technology roadmapping adotada neste trabalho é a de um método flexível cujo objetivo principal é auxiliar no planejamento estratégico de desenvolvimento de mercado, produto e tecnologia de maneira integrada ao longo do tempo (Albright \& Kappel, 2003; Kappel, 2001; Phaal et al., 2001, 2004),

As raízes do TRM podem ser creditadas à indústria automobilística norteamericana. Entretanto, as primeiras organizações a aplicá-lo com sucesso foram as grandes corporações de tecnologia Corning e Motorola, no final da década de 70, início dos anos 80 (Drummond, 2005). A primeira publicação acadêmica sobre o technology roadmapping data do final da década de 1980, de autoria de Willyard \& McCless (1987), apresentando o método e suas vantagens no planejamento tecnológico para empresas.

De acordo com Phaal et al. (2004), o technology roadmapping representa uma técnica poderosa para suportar o gerenciamento e planejamento tecnológico, especialmente para explorar e comunicar interações dinâmicas entre recursos, objetivos organizacionais e mudanças no ambiente. Visa ajudar a identificar, selecionar e desenvolver alternativas tecnológicas para satisfazer um conjunto de necessidades do produto (Garcia \& Bray, 1997). Desse modo, é um método impulsionado pelo mercado (market pull), isto é, pelas inovações tecnológicas necessárias para as empresas atenderem a mercados futuros, e não pela tecnologia em si mesma (technology push). O que se busca construir é uma visão de futuro (onde a organização pretende chegar) e quais são as tecnologias necessárias para se chegar até lá. 
Organizações que usam TRM como um processo de planejamento estratégico se beneficiam pelas seguintes possibilidades (Santos, 2011): (i) prover o desenvolvimento, comunicação e implantação das estratégias ao longo do tempo de maneira a integrar as áreas de mercado, produto e tecnologia; (ii) fortalecer e estruturar o processo de planejamento e monitoramento do ambiente tecnológico e de mercado, orientando e auxiliando o processo de tomada de decisão de desenvolvimento numa perspectiva de médio e longo prazo; (iii) promover visibilidade/transparência da lógica de planejamento ao explicitar as conexões entre mercado, produto e tecnologia por intermédio de um mapa estratégico; (iv) facilitar a visualização das deficiências (gaps) no processo de alinhamento das metas de médio e longo prazo e nas atividades presentes na empresa; (v) possibilitar a integração do market pull com o technology push; ou seja, incluir tanto os produtos demandados pelo mercado quanto os ofertados pela capacidade tecnológica; (vi) auxiliar na definição das prioridades para o desenvolvimento e, por consequência, na tomada de decisões relativas a investimento; (vii) gerenciar dados, planos de produto e objetivos em alto nível; (viii) capacitar descoberta de reuso da tecnologia e oportunidades de sinergismo; (ix) revelar lacunas, desafios e incertezas em relação a produto, tecnologia e planos de capacitação; (x) revelar fraquezas de estratégia em longo prazo antes que se tornem críticas; (xi) comunicar e prover visibilidade na direção de programa estratégico em torno da organização; (xii) habilitar crescimento de portfólio de produto em linha com demandas corporativas e de mercado; e (xiii) prover direcionamento para projetar grupos de pessoas e capacitá-las a enxergar rapidamente mudanças em eventos ou direções estratégicas.

\subsubsection{Technology Roadmaps}

O termo technology roadmap consiste no documento gerado pelo método TRM (Phaal et al., 2001, 2004). Existem muitas aplicações para os roadmaps, desde pesquisas científicas de ciência e tecnologia, previsão para políticas governamentais ou para determinado setor industrial, até estudos da evolução de produtos ou tecnologias. Algumas vezes o uso do roadmapping pode ser utilizado para comunicar consumidores e fornecedores. Uma característica importante dos roadmaps é sua apresentação concisa que possibilita uma discussão estruturada e construtiva de processos de prospecção tecnológica.

Garcia \& Bray (2007) classificam os roadmaps em três tipos: (i) roadmap de produto, que é dirigido pelas necessidades de produto e/ou processo; (ii) roadmap orientado para uma determinada tecnologia, que foca a previsão de desenvolvimento e comercialização de uma nova ou emergente tecnologia, a posição competitiva da empresa com relação à tecnologia e como esta tecnologia emergente e a posição competitiva da empresa irá se desenvolver e (iii) roadmap orientado a um determinado assunto, que objetiva identificar problemas e suas consequências para o planejamento estratégico e orçamento.

Os roadmaps podem apresentar várias formas, mas a aproximação mais comum é aquela chamada genérica (Phaal et al., 2001) que consiste em uma representação gráfica baseada no tempo, compreendendo um número de camadas que abordam parâmetroschaves como mercado, produto e tecnologia ao longo do tempo para uma parte do negócio. Phaal et al. (2004) propuseram um roadmap de múltiplas camadas, por se apresentar de forma mais flexível, com as seguintes dimensões: (i) tempo: esta dimensão pode ser adaptada para se adequar à situação particular, em termos de horizonte de tempo 
(tipicamente curto prazo em setores como e-commerce e software, e longo prazo para a indústria aeroespacial e infraestrutura) e (ii) camadas: o eixo vertical do roteiro é crítico, já que isso precisa ser projetado para se adequar à organização e a problemas específicos que estão sendo abordados. A Figura 1.5 mostra uma arquitetura de roadmap generalizada.

Os diferentes tipos de camadas nos roadmaps são listados, destacando a flexibilidade da abordagem em fornecer uma estrutura para apoiar o planejamento estratégico. As camadas superiores referem-se ao propósito organizacional que está impulsionando o roteiro (know-why). As camadas inferiores referem-se aos recursos (particularmente o conhecimento tecnológico) que serão implantados para atender à demanda das camadas superiores do roadmap (know-how). As camadas intermediárias do roadmap são cruciais, fornecendo um mecanismo de ponte ou entrega entre o objetivo e os recursos (know-what).

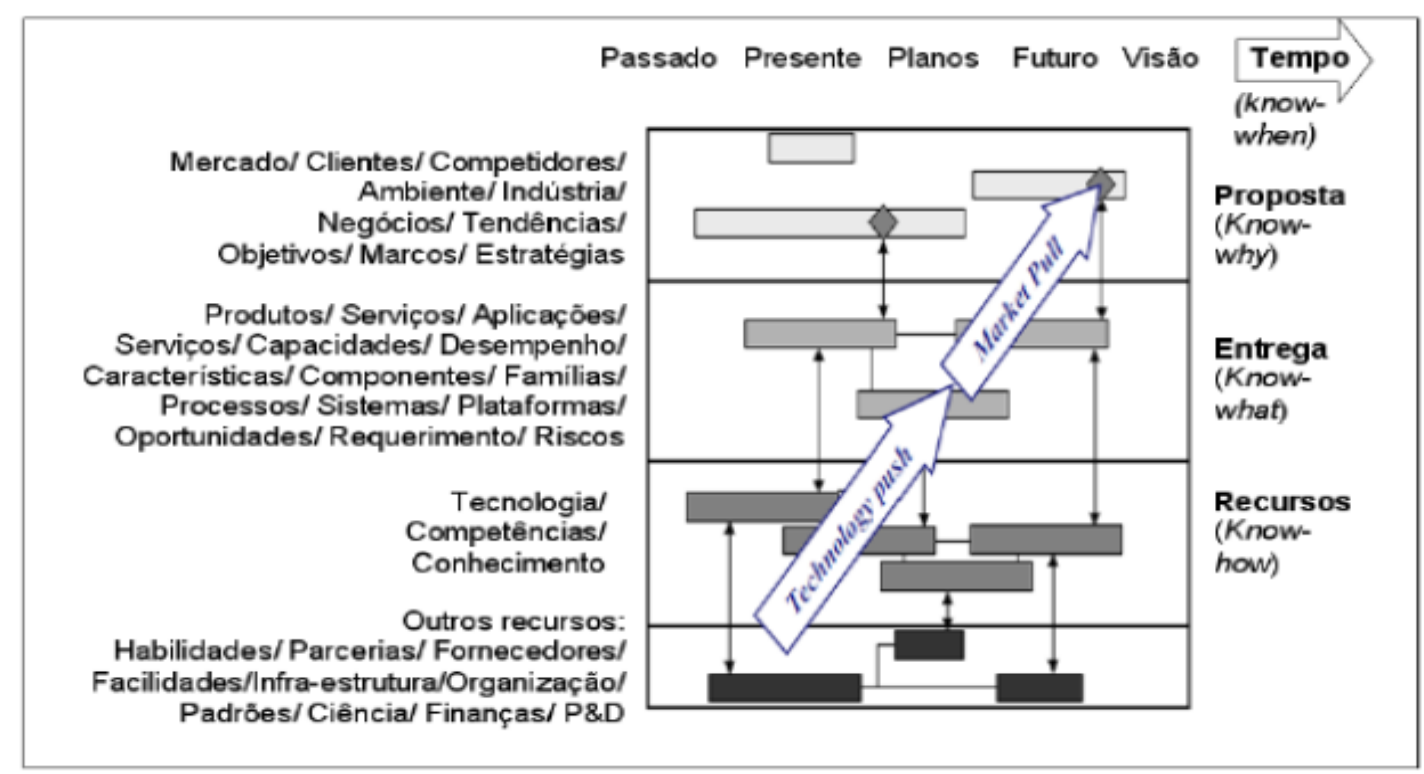

Figura 1.5. Arquitetura de roadmap generalizada (Phaal et al., 2004)

Frequentemente, a camada intermediária concentra-se no desenvolvimento de produtos, já que essa é a rota pela qual a tecnologia é frequentemente implantada para atender às necessidades do mercado e dos clientes. Entretanto, em outros contextos, podem ser alocados na camada intermediária serviços, capacidades, sistemas, riscos ou oportunidades, de modo a entender como a tecnologia pode ser entregue para fornecer benefícios à organização e às partes interessadas.

Além das informações contidas nas camadas em uma base de tempo, outras informações podem ser armazenadas no roadmap, como ligações entre objetos em camadas e subcamadas (de vários tipos possíveis).

\subsection{Método Technology Roadmap}

Os processos de aplicação do technology roadmapping encontrados na literatura foram aqueles desenvolvidos por Phaal et al. (2001, 2004), Albright \& Kappel (2003), Garcia \& Bray (1997), Loureiro (2010), Santos (2011) e Borschiver \& Silva (2016). Tais 
processos preveem a utilização de outras ferramentas de prospecção tecnológica como Brainstorming, Delphi/Painéis de especialistas, análise de cenário, uso de documentos de patentes e artigos científicos, dentre outras.

Para a elaboração do technology roadmap sugerido neste capítulo, foi adotada uma versão simplificada das metodologias propostas por Loureiro (2010), Santos (2011) e Borschiver \& Silva (2016), integrado às propostas sugeridas por autores da área de Sistemas de Informação (Ribeiro \& Araújo, 2019) (Araújo et.al. 2018a) (Araújo e Chueri, 2018) (Araújo et.al. 2018b) (Araújo et.al., 2017) (Araújo, 2016) (Paula \& Araújo, 2018) (Procaci et.al., 2016).

O método apresenta cinco etapas, descritas a seguir: (i) etapa 1 - Levantamento preliminar sobre o tema, (ii) etapa 2 - Busca de informação tecnológica; (iii) Definição da estrutura e condições de contorno do roadmap; (iv) etapa 4 - Construção do Roadmap e (v) etapa 5 - Análise do Roadmap A Figura 1.6 apresenta as etapas principais que serão detalhadas nas seções a seguir. O método será ilustrado tendo como base o contexto de pesquisa na temática de Cidades Inteligentes.

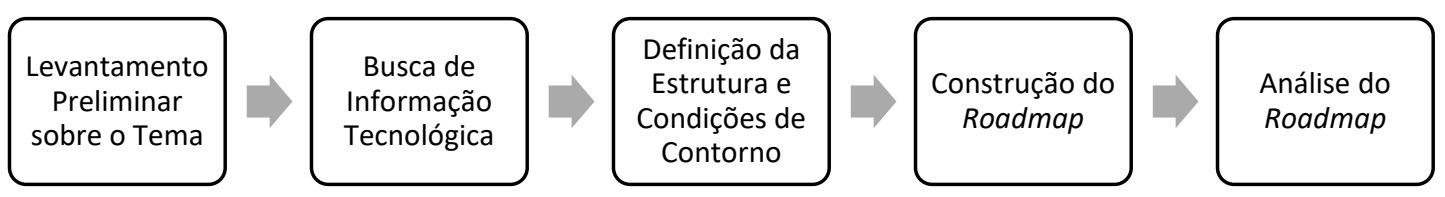

Figura 1.6. Etapas do TRM proposto (Elaboração das autoras)

\subsubsection{Etapa 1: Levantamento preliminar sobre o tema}

Nesta etapa, é necessário escolher um tema objeto de estudo para a prospecção e realizar um levantamento de informações preliminar sobre o mesmo, afim de conhecer o assunto e identificar termos-chave. No contexto de pesquisas científicas, boa parte da informação para esta etapa provem da definição do referencial teórico e principais conceitos da área sob estudo.

Segundo Pardo (2011 apud ABDI, 2017) Cidade Inteligente é aquela que "infunde informações em sua infraestrutura física para melhorar as conveniências, facilitar a mobilidade, adicionar eficiência, economizar energia, melhorar a qualidade do ar e da água, identificar problemas e corrigi-los rapidamente, recuperar-se rapidamente de desastres, coletar dados para tomar melhores decisões, implantar recursos de forma eficaz e compartilhar dados para ativar a colaboração entre entidades e domínios".

SI desempenham um papel fundamental nas Cidades Inteligentes, pois atuam como plataforma para agregar e processar informações e dados, possibilitando uma melhor compreensão sobre o funcionamento da cidade, em termos de consumo de recursos, serviço e estilos de vida: Big Data, Open Data, Internet das Coisas, acessibilidade, gerenciamento inteligente de dados, cibersegurança, banda larga aberta, redes de sensores entre outros elementos são essenciais no contexto das Cidades Inteligentes, formando ecossistemas de informação complexos.

A efetiva contribuição dos SI ao fornecimento de serviços e utilidades públicas nas cidades varia conforme o setor sob análise, mas podem ser citados os seguintes 
aspectos: mobilidade, iluminação, saneamento básico, gestão de água e esgoto, gestão de resíduos sólidos, segurança pública, gestão energética, saúde pública e educação pública.

\subsubsection{Etapa 2: Busca de Informação Tecnológica}

O objetivo desta etapa é mapear as informações tecnológicas para elaborar o roadmap. As fontes de informação tecnológica são os pedidos de patentes e patentes concedidas, (lembrando que as mesmas já estão mais próximo de sua fase comercial, em especial as patentes concedidas) e artigos científicos (lembrando que os mesmos estão um grau inicial de desenvolvimento da tecnologia tendo em vista se encontram ainda em fase de estudo acadêmico).

Araújo e Chueri (2018) e Araújo et.al. (2018a) descrevem um processo para busca de informação tecnológica em bases de informação sobre propriedade intelectual baseado em processos de mapeamentos e/ou revisões sistemáticas de literatura científica $\mathrm{O}$ processo compreende as fases e atividades conforme apresentadas na Tabela 1.4. Detalhes sobre como realizar esta busca podem ser encontrados na referência supramencionada.

Tabela 1.4. Fases e atividades para a busca de informação tecnológica em bases de Patentes. Fonte: (Araujo et al, 2018a)

\begin{tabular}{|c|c|}
\hline Fase & Atividades \\
\hline 1) Planejamento & $\begin{array}{l}\text { - Formular questão para a busca } \\
\text { - Identificar palavras-chave } \\
\text { - Montar string de busca } \\
\text { - Identificar classificação internacional (CIP) } \\
\text { - Decidir quanto ao período de tempo } \\
\text { - Definir critérios de inclusão e de exclusão } \\
\text { - Selecionar base(s) de dados }\end{array}$ \\
\hline 2) Execução & $\begin{array}{l}\text { - Realizar busca nas bases de dados } \\
\text { - Organizar resultado das buscas } \\
\text { - Selecionar patentes }\end{array}$ \\
\hline 3) Análise & - Analisar patentes selecionadas \\
\hline 4) Relato & - Gerar relatórios/publicações \\
\hline
\end{tabular}

Para efeito de ilustração, apresentamos uma busca simplificada ${ }^{5}$ na base de dados do INPI com as palavras-chave "cidades inteligentes" e "cidade inteligente", com retorno de 12 patentes. Considerando as patentes (pedidos e concedidas) depositadas no período de 2010 a 2018, foram encontrados 9 documentos (todos pedidos de patente, ou seja, em processo de análise). A partir da leitura dos resumos e do quadro reivindicatório de cada documento, os mesmos foram categorizados, conforme Tabela 1.5. As dimensões utilizadas para categorização foram estipuladas de forma subjetiva, de acordo os resultados da etapa anterior combinadas com a análise das patentes encontradas: Tecnologia utilizada, Utilidade, Principal Interessado (Clientes). Com o objetivo de identificar os principais atores (players) atuando no tema, foi incluída a informação sobre o depositante da patente.

\footnotetext{
${ }^{5}$ Realizada em janeiro de 2019
} 
Tabela 1.5 - Informações obtidas sobre patentes em Cidades Inteligentes no INPI

\begin{tabular}{|c|c|c|c|c|}
\hline Patente & Tecnologia & Utilidade & Interessado & Depositante \\
\hline $102016021792-0$ & $\begin{array}{l}\text { Internet das } \\
\text { Coisas }\end{array}$ & Mobilidade Urbana & $\begin{array}{l}\text { Pessoas, Usuários de } \\
\text { carros }\end{array}$ & $\begin{array}{l}\text { Universidade } \text { Estadual do } \\
\text { Maranhão }\end{array}$ \\
\hline $202016020697-4$ & $\begin{array}{l}\text { Sensor e Conexão } \\
\text { sem fio }\end{array}$ & Mobilidade Urbana & Usuários de carro & $\begin{array}{l}\text { Soluções em conectividade } \\
\text { das coisas indústria e } \\
\text { comercio de produtos } \\
\text { eletrônicos ltda. - ME }\end{array}$ \\
\hline $102013004342-7$ & Sensor & $\begin{array}{l}\text { Saneamento Básico, } \\
\text { Gestão Ambiental, } \\
\text { Gestão Energética } \\
\text { Mobilidade Urbana }\end{array}$ & $\begin{array}{l}\text { Pessoas, Usuários de } \\
\text { carro, Residências, } \\
\text { Comércios }\end{array}$ & Antonio Valerio Netto \\
\hline $102012026807-8$ & $\begin{array}{l}\text { Rede de } \\
\text { comunicações } \\
\text { integradas }\end{array}$ & $\begin{array}{l}\text { lluminação, } \\
\text { Saneamento Básico, } \\
\text { Gestão de Água e } \\
\text { Esgoto, Gestão } \\
\text { Energética, } \\
\text { Mobilidade Urbana }\end{array}$ & $\begin{array}{l}\text { Pessoas, usuários de } \\
\text { carro, Residências, } \\
\text { Comércios }\end{array}$ & $\begin{array}{l}\text { Smartgreen } \\
\text { Desenvolvimento } \\
\text { Tecnologias S/A. }\end{array}$ \\
\hline 1020120159970 & $\begin{array}{l}\text { Rede de } \\
\text { comunicações } \\
\text { integradas }\end{array}$ & $\begin{array}{l}\text { Iluminação, } \\
\text { Saneamento Básico, } \\
\text { Gestão de Água e } \\
\text { Esgoto, Gestão } \\
\text { Energética, } \\
\text { Mobilidade Urbana }\end{array}$ & $\begin{array}{l}\text { Pessoas, Usuários de } \\
\text { carro, Residências, } \\
\text { Comércios }\end{array}$ & $\begin{array}{l}\text { Smartgreen } \\
\text { Desenvolvimento } \\
\text { Tecnologias S/A de }\end{array}$ \\
\hline $1004539-2$ & Outros & Gestão de Negócios & Comércios & $\begin{array}{l}\text { Roberto Jakson Rodrigues } \\
\text { Leite }\end{array}$ \\
\hline 102017 012748-6 & Outros & $\begin{array}{l}\text { Gestão de Resíduos, } \\
\text { Saneanento Basico }\end{array}$ & $\begin{array}{l}\text { Residências, } \\
\text { Comércios }\end{array}$ & Willian Oliveira de Souza \\
\hline $112018000150-3$ & Sensor & Gestão Energética & Residências & University of South Africa \\
\hline $10201501038-3$ & GPS & Mobilidade Urbana & Pessoas & $\begin{array}{lll}\text { Universidade } & \text { Federal da } \\
\text { Bahia } & \end{array}$ \\
\hline
\end{tabular}

No que se refere à busca de artigos científicos, protocolos de revisão de literatura, como o proposto por Kitchenham (2004), têm sido largamente utilizados pela comunidade científica e podem oferecer mecanismos valiosos para a análise do conteúdo de artigos científicos. Como mencionado na seção 1.3.1.2, nestes protocolos são utilizadas bases indexadas nacionais e internacionais. Para efeito de ilustração apenas, utilizamos uma busca simplificada na base de dados da iSys - Revista Brasileira de Informação ${ }^{6}$. Foram encontrados 2 artigos científicos para o período entre 2010 e $2018^{7}$. A partir da leitura dos resumos de cada artigos, os mesmos foram categorizados com a mesma taxonomia utilizada na busca de patentes (Tabela 1.6).

Tabela 1.6 - Informações obtidas nos artigos científicos disponíveis na iSys

\begin{tabular}{|c|c|c|c|c|}
\hline Artigos & Tecnologia & Utilidade & Interessado & Instituição \\
\hline $\begin{array}{lr}\text { Investigando a } & \text { Mobilidade } \\
\text { Urbana Através de Dados Abertos } \\
\text { Governamentais } & \text { Enriquecidos } \\
\text { com Proveniência } & \\
\end{array}$ & GPS & $\begin{array}{l}\text { Mobilidade } \\
\text { Urbana }\end{array}$ & $\begin{array}{l}\text { Pessoas em } \\
\text { geral, } \\
\text { Usuários de } \\
\text { carros }\end{array}$ & $\begin{array}{l}\text { UFRRJ } \\
\text { UFRJ }\end{array}$ \\
\hline $\begin{array}{l}\text { Um Modelo Computacional para } \\
\text { Cidades Inteligentes Assistivas }\end{array}$ & GPS & $\begin{array}{l}\text { Acessibilidade, } \\
\text { Saúde Pública }\end{array}$ & $\begin{array}{l}\text { Pessoas com } \\
\text { deficiências }\end{array}$ & UNISINOS \\
\hline
\end{tabular}

\footnotetext{
${ }^{6}$ http://www.seer.unirio.br/index.php/isys

${ }^{7}$ Consulta realizada em janeiro de 2019
} 


\subsubsection{Etapa 3: Definição da estrutura e condições de contorno do roadmap}

Com base nas análises obtidas pela busca de informação realizada nas etapas anteriores, é possível delimitar a estrutura do roadmap e suas condições de contorno, principalmente seu horizonte de tempo. A estrutura do roadmap segue a forma de apresentação genérica proposta por Phaal (2001) e apresentada na Figura 1.5, compreendendo três camadas que abordam os parâmetros-chaves (as linhas ou raias no roadmap): objetivos, capacidades/competências e conhecimento. A definição de cada uma destas camadas depende diretamente da análise qualitativa do resultado da busca de informações.

Em nosso exemplo, associamos a primeira camada - objetivo - aos clientes ou principais interessados das tecnologias apresentadas, o público-alvo para os quais as tecnologias ligadas a cidades inteligentes estão sendo desenvolvidas. Na segunda camada - capacidade/competências - relacionamos as aplicações ou utilidade das tecnologias, o que precisa ser desenvolvido para atingir os clientes identificados na primeira camada. Para a terceira camada - conhecimento - foram relacionadas as tecnologias utilizadas nas invenções, o que é necessário investir para que as utilidades (segunda camada) sejam melhoradas de modo a atingir os clientes especificados (primeira camada) dentro do horizonte de tempo desejado.

Para definição de curto, médio e longo prazo, adotamos a proposta de Loureiro (2010) Borschiver \& Silva (2016), determinando que no curto prazo deverão ficar as patentes concedidas, médio prazo os pedidos de patentes e no longo prazo os artigos científicos - conforme critério de análise do grau de desenvolvimento da tecnologia e sua fase comercial.

\subsubsection{Etapa 4: Construção do Roadmap}

A construção do roadmap segue as operações sugeridas por Santos (2011 p.257): i) construir uma tabela/planilha onde as linhas contêm os elementos direcionadores dos parâmetros-chave e as colunas contém as dimensões de horizonte de tempo; ii) nos cruzamentos das linhas e colunas, identificar os resultados da busca de informação tecnológica encontrados; iii) conectar verticalmente os elementos direcionadores de uma mesma patente/artigo encontrado.

Para o exemplo, o desenho do roadmap seria conforme o apresentado na Figura 1.7. No exemplo, como não foi encontrada nenhuma patente concedida na base de dados do INPI, optou-se por juntar o curto e médio prazo com os pedidos de patente e no longo prazo os artigos científicos. Adicionalmente, é possível inserir no roadmap os atores depositantes patentes e/ou instituições de pesquisa.

\subsubsection{Etapa 5: Análise do Roadmap}

A análise do roadmap é, em última instância, uma interpretação livre e segue os interesses de análise de seu elaborador. É importante compreender que as camadas intermediárias do roadmap representam um mecanismo de alcance ou entrega entre o objetivo e os recursos de conhecimento disponíveis. O roadmap permite construir uma visão de futuro (onde se pretende chegar, ou no caso, quais pessoas que se deseja atingir) e quais são as tecnologias necessárias para se chegar até lá.

Para o caso específico do roadmap do exemplo, as informações coletadas (lembrando que são ilustrativas e de escopo bastante limitado - INPI e iSyS) nos 
permitiriam observar, por exemplo, que os esforços inovadores no curto/médio prazo com relação a utilidade relacionada às cidades inteligentes se concentra no tema mobilidade urbana de modo a atender as pessoas em geral e os usuários de carros. É de conhecimento geral que nas cidades modernas o deslocamento de pessoas nos diversos modais de transporte tem despertado o interesse dos governantes e principais fornecedores.

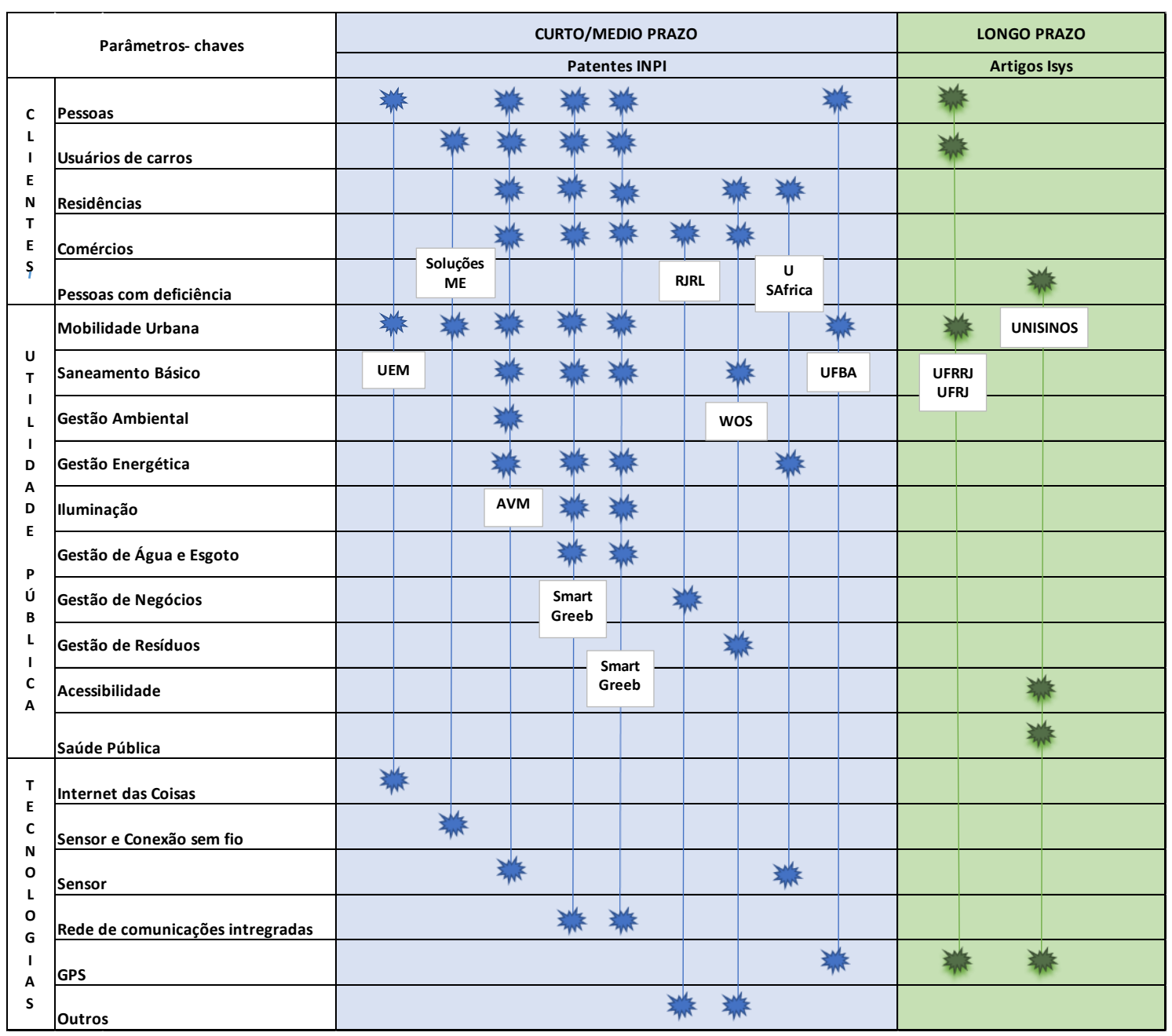

Figura 1.7. Roadmap exemplo para o tema de Cidades Inteligentes

O roadmap nos permite, ainda identificar lacunas de curto, médio e longo prazo de áreas de mercado e público-alvo onde é possível explorar oportunidades de pesquisa, desenvolvimento de produtos e propriedade intelectual (por exemplo, aplicações em iluminação, gestão de água e esgoto, negócios, resíduos, acessibilidade e saúde pública). Em termos de tecnologias, a Internet das Coisas aparece no roadmap ainda pouco explorada, apontando para oportunidades de investimento em pesquisa e ativos de propriedade intelectual.

Podemos observar ainda, a partir das informações dos principais atores presentes no roadmap, quem seriam, a curto, médio e longo prazo, potenciais parceiros de pesquisa e/ou transformação de pesquisas em produtos. Além disso, da análise dos players do roadmap, podemos citar que, no longo prazo, as universidades UFRRJ, UFRJ e UNISINOS poderiam ser agrupadas em um cluster pois apresentam o mesmo perfil 
relacionado às tecnologias (no caso, o uso do GPS), uma vez que estão orientando suas pesquisas neste assunto. De posse dessa informação, novos players podem planejar suas pesquisas de modo a evitar duplicação de esforços e propor parcerias de modo a atingir objetivos comuns.

\subsection{Conclusão}

Este minicurso teve como objetivo apresentar o uso de roadmaps como um instrumento para monitorar e analisar os esforços inovadores na área de Sistema de Informação. Apresentamos um exemplo de seu uso no contexto das cidades inteligentes, tema atual e que tem despertado o interesse especial da comunidade científica.

A realização de estudos prospectivos não é um exercício de previsão, mas sim um esforço para obter descrições consistentes de possíveis situações futuras, revelando informações relevantes sobre o caminho entre o status atual e o futuro, auxiliando nas decisões a serem tomadas. Nesse sentido, o método pode ser uma ferramenta valiosa para a prospecção tecnológica e apoio às decisões de planejamento, mantendo-se dentro dos limites do conhecimento científico e propondo o panorama viável dentro do horizonte de tempo.

A busca de informação tecnológica torna-se uma atividade importante cujo conteúdo não pode ser negligenciado tanto por pesquisadores como empreendedores. As bases de patentes e artigos científicos tem se mostrado valiosas fontes de informação disponíveis na literatura, ainda que apresentem algumas limitações tais como, pouco uso de patentes pela comunidade científica, devido a linguagem particular.

Por fim, o uso de roadmaps no planejamento estratégicos das linhas de pesquisa realizadas em empresas, startups, universidades ou grupos de pesquisa, em especial na área de Sistemas de Informação, podem auxiliar na identificação de áreas de pesquisa e/ou desenvolvimento tecnológico, bem como identificar os principais players visando a propor parcerias estratégicas entre estas organizações.

\section{Referências}

ABDI - Agência Brasileira de Desenvolvimento Industrial (2017). "Cidades Inteligentes". Documento de referência. Ambiente de demonstração de tecnologias para cidades inteligentes. Produto 2B - Versão Final. Dezembro de 2017.

Abreu, J.C. (2017). "Prospecção Tecnológica aplicada na otimização da concessão de patentes no Brasil: estudo de caso em patentes de medicamentos imunossupressores. 342 p. Tese de Doutorado. Instituto de Economia, UFRJ, Rio de Janeiro.

Albright, R. E. e Kappel, T. A. (2003). "Roadmapping in the corporation". Research Technology Management, v.46 n.2, p.31-40, 2003.

Alencar, M.S. (2016) "Patentes: Fonte de informação fundamental para inovação". Palestra proferida na disciplina Estudos Dirigidos à Inovação PPGI-UNIRIO em novembro/2016.

Araujo, R.M., Alves, A., Gouvea, M.T., Anastassiu, M., Gomes, S., Frattini, V. (2018a) "Levantamento de Informação Tecnológica para Pesquisa: Uma Proposta de Sistematização." Relatórios Técnicos da UNIRIO (Relate-DIA), vol 11, no 1. http://www.seer.unirio.br/index.php/monografiasppgi/article/view/7126 
Araujo, R.M. e Chueri, L.O.V. (2018) "Da Pesquisa à Inovação em Sistemas de Informação". In: Rodrigo Santos, André Martinotto. (Org.). https://www.ucs.br/site/midia/arquivos/topicos-sistema-informacao.pdf. 1ed. Porto Alegre: Sociedade Brasileira de Computação, v. 1, p. 41-73.

Araujo, R. M.; Silva, V. C. M. ; Gomes, S. B. ; Bessa, A. T. ; Reis, L. C. D. ; Dutra, E. ; Estruc, M. A. (2018b) “Onde está a Inovação?”. Perspectivas de inovação para pesquisas na área de Sistemas de Informação. 2018b.

Araujo, R.M., Paula, L.G. (2017). “Avaliação da Inovação.” Em: Araujo, R.M. e Chueri, L.O.V. (eds) Pesquisa \& Inovação: Visões e Interseções. PUBL!T Soluções Editoriais. p. 203-215.

Araujo, R. M.; Silva, C. K. P. E. ; Sacramento, C. ; Confort, V. T. F. ; Moncores, M. C. ; Pinheiro, A. H. S. E. M. ; Amorim, P. F. ; Bastos, C. A. R. ; Oliveira Junior, C. R. ; Almeida, G. O. (2017) "Trilhando trajetórias de pesquisar \& inovar - um ensaio coletivo". 2017.

ARAUJO, R. M.. Estudos Dirigidos à Inovação: Uma experiência na formação de pesquisadores-inovadores em Sistemas de Informação. In: Encontro de Inovação em sistemas de Informação, 2016, Florianópolis. III Encontro de Inovação em Sistemas de Informação. Porto Alegre: Sociedade Brasileira de Computação, 2016.

Barbieri, J.C. (2007). Organizações Inovadoras Sustentáveis. In: Organizações Inovadoras Sustentáveis: Uma Reflexão sobre o Futuro das Organizações. São Paulo: Editora Atlas.

Battaglia, M.G.B. (1999) "A Inteligência Competitiva Modelando o Sistema de Informação de Clientes - Finep”. Ci.Inf. Brasília, v. 29, n. 2, p. 200-214, mai./ago.

Borschiver, S. (2007). "Levantamento, classificação e categorização dos indicadores da atividade de PD\&E”. RPCA, Rio de Janeiro, v. 1, n. 1, set./dez. 2007.

Borschiver, S. e Silva, A.L.R. (2016) Technology roadmap: planejamento estratégico para alinhar mercado-produção-tecnologia. Rio de Janeiro: Interciência.

Burlamarqui, L. e Proença, A. (2003). "Inovação, Recursos e Comprometimento: em Direção a uma Teoria Estratégica da Firma". Revista Brasileira de Inovação, v. 2, n. 1, Janeiro/Junho 2003.

Coates, V. et al. (2001). "On the future of technological foresight". Technological Forecasting and Social Change. New York, v. 67, p 1-17.

Drummond, P. H. F.(2005). "O planejamento tecnológico de uma empresa de base tecnológica de origem acadêmica por intermédio dos métodos technology roadmapping (TRM), technology stage-gate (TSG) e processo de desenvolvimento de produtos (PDP) tradicional”. Dissertação - Engenharia de Produção, UFMG, Belo Horizonte, 2005.

França, J.G.E. (2006) "Biocombustíveis: Desenvolvimento Tecnológico da Agroindústria”. Seminário Internacional de Biocombustíveis - OLADE. Brasília, abr.

Freire, A. (1998). Inovação Novos Produtos, Serviços e Negócios para Portugal, Editora Verbo, Lisboa, 1998.

Garcia, M. L. e Bray, O. H. (2010). "Fundamentals of technology roadmapping”. Sandia National Laboratories. Disponível em: www.sandia.gov/PHMCOE/pdf/Sandia'sFundamentalsofTech.pdf. Acesso em: out. 2010. 
Guimaraes, D.C.; Cruz, C.A.B.; Alves, M.B.N. e Paixão, A.E.A. (2018). Propriedade Intelectual e Programas de Computador: um mapeamento de programas aplicados na Administração". In: Propriedade intelectual, tecnologias e inovação. Russo, S.L.; Santos, A.V.; Zan, F.R.; e Priesnitz, M.C. (organizadores). - Aracaju: Associação Acadêmica de Propriedade Intelectual, 2018.

Jagher, T. (2017) 'Busca em Banco de Dados de Patentes. Agência de Inovação/ UTFPR”. Disponível em:

http://www.utfpr.edu.br/medianeira/estrutura/diretorias/direc/downloads/procedimentopa rapesquisaumapatente.pdf. Acesso em: 11/10/2017.

Jannuzzi, C.A.S.C. e Montalli, K.M.L. (1999) “Informação tecnológica e para negócios no Brasil: introdução a uma discussão conceitual". Ciência da Informação, Brasília DF, v. 28 , n. 1, p. 28-36.

Jannuzzi, A.H.L. et al. (2007) “Gestão Estratégica de Portifólio de Patentes na Indústria Farmacêutica”. In: XXVII Encontro Nacional de Engenharia de Produção, Foz do Iguaçu, PR. 09 a 11 de outubro de 2007.

Jannuzzi, A.H.L. and Souza, C.G. (2008) "Patentes de invenção e artigos científicos: especificidades e similitudes”. RBPG, Brasília, v. 5, n. 9, p. 103-125.

Lee, S. e Park, Y. (2005). "Customization of technology roadmaps according to roadmapping purposes: Overall process and detailed modules". Technological Forecasting \& Social Change, v.72, p.567-583.

Lima, C.M. (2005) "Mapeamento Tecnológico de Astaxantina”. Dissertação (Mestrado) - Programa de Pós-Graduação em Tecnologia de Processos Químicos e Bioquímicos, Escola de Química, UFRJ, Rio de Janeiro, 2005.

Loureiro, A.M.V. (2010). "O emprego do método technology roadmapping em adesivos e selantes aplicados à construção civil". 330 p. Tese de Doutorado. Programa de Pósgraduação na Escola de Química, UFRJ, Rio de Janeiro.

Kappel, T. A. (2001). "Perspectives on roadmaps: how organizations talk about the future". The Journal of Product Innovation Management, v.18, p.39-50.

Kitchenham, B. (2004). "Procedures for Performing Systematic Reviews". Joint Technical Report Software Engineering Group, Department of Computer Science Keele University, United King and Empirical Software Enginneering, National ICT Australia Ltd, Australia, 2004.

Macias-Chapula, C.A. (1998) "O papel da informetria e da cienciometria e sua perspectiva nacional e internacional”. Ci. Inf., Brasília, v. 27, n. 2, p. 134-140, mai/ago.

Manual de Oslo (2006)."The Organisation for Economic Co-operation and Development OECD”.

Mattos Neto, P. (2005) "Planejamento de novos produtos por intermédio do método technology roadmapping (TRM) em uma pequena empresa de base tecnológica do setor de internet móvel". Dissertação de Mestrado. Engenharia de Produção, Universidade Federal de Minas Gerais, Belo Horizonte, Minas Gerais.

Nunes, M.A.S.N. (2014) "Propriedade Intelectual e Industrial em Jogos e noções sobre prospecção de tecnologia: em direção à apropriação nacional/internacional dos ativos 
brasileiros desenvolvidos". In: Tutoriais do SBGAMES 2014, $1^{\text {a }}$ ed, Porto Alegre: EdiPUCRS, 2014, v.1, p. 1-35.

Nunes, M. A. S. N., Pinheiro-Machado, R. (2017). "Propriedade Intelectual e Busca de Informação Tecnológica na área da Computação". Em: Araujo, R.M. e Chueri, L.O.V. (eds) Pesquisa \& Inovação: Visões e Interseções. PUBL!T Soluções Editoriais. p. 6792.

Oliveira, T. (2005). "Um Estudo de Prospecção e de Estratégias de Inovação: O caso dimetil éter (DME) e seu uso como combustível”. Rio de Janeiro, 132 f. Dissertação (Mestrado) - Escola de Química, UFRJ, Rio de Janeiro.

Paula, F. C. ;Araujo, R. M. (2018) "Tecnologias no Cotidiano Escolar: Levantamento de Patentes no Brasil e Estados Unidos de 2000 a 2017’. In: Latin American Conference on Learning Technologies, 2018, São Paulo. XIII Latin American Conference on Learning Technologies, 2018.

Peres, B.S. (2005) “Estudo e Mapeamento Tecnológico do Interferon”, 133 f. Dissertação (Mestrado) - Programa de Pós-Graduação em Tecnologia de Processos Químicos e Bioquímicos, Escola de Química, UFRJ, Rio de Janeiro.

Phaal, R., Farrukh, C. J. P. e Probert, D. R. (2004).“Technology roadmapping - A planning framework for evolution and revolution. Technological Forecasting \& Social Change, v.71, p.5-26.

Phaal, R., Farrukh, C. J. P. e Probert, D. R. (2001) "T-Plan: The fast start to technology roadmapping - Planning your route to success". Cambridge University, Institute of Manufacturing, UK, October.

PINTEC (2016). Pesquisa de inovação: 2014 / IBGE, Coordenação de Indústria. - Rio deJaneiro : IBGE.

Procaci, T. B.; Araujo, R. M.; Siqueira, S.W.M. e Nunes, B. P. (2016) "Prospecção Tecnológica: Levantamento de Patentes, Atuação da Academia e Potenciais Inovações em Ambientes de Aprendizagem no Brasil de 2000 a 2015". iSys: Revista Brasileira de Sistemas de Informação, v. 9, p. 69-88, 2016.

Ribeiro, M.F. e Araujo, R.M. (2019) "ICT in Education Technology Roadmap for Sustainable Development - Innovative Efforts of Brazilian High Level Education and Research Institutions".World Symposium on Sustainability Science and Research Implementing. The 2030 United Nations Agenda for Sustainable Development.

Ries, E. (2018) “O Estilo Startup”. 368 p. Editora Leya.

Santos, M.F.R.F. (2011). "Elaboração do technology roadmap para biorrefinaria de produtos da lignina no Brasil". 307 p. Tese de Doutorado. Programa de Pós-graduação na Escola de Química, UFRJ, Rio de Janeiro.

Schaller, R. (2004). "Technological Innovation in The Semiconductor Industry: A Case Study Of The International Technology Roadmap For Semiconductors (ITRS)". Tese de Doutorado. Universidade George Mason, EUA.

Souza, D.L.O. (2003). "Ferramentas de Gestão de Tecnologia: Um Diagnóstico de Utilização nas Pequenas e Médias Empresas Industriais de Curitiba". Curitiba, 119f. Dissertação (Mestrado) - Programa de Pós-Graduação em Tecnologia, CEFET, Paraná. 
Souza, C.G. et al. (2007) "Mapeamento da Informação Técnica como Subsídio às Atividades de P\&D: Caso da Tecnologia de Ligas com Memória de Forma”. In: XXVII Encontro Nacional de Engenharia de Produção, Foz do Iguaçu, PR. 09 a 11 de outubro de 2007.

Teixeira, L.P. (2013). "Prospecção tecnológica: importância, métodos e experiências da Embrapa Cerrados. Planaltina, DF: Embrapa Cerrados.

Tigre, P.B. (2006) .Gestão da inovação: a economia da tecnologia do Brasil. Rio de Janeiro: Elsevier.

Weiss, S.L.I. “Artigo Científico - Orientações para sua elaboração”. s/d. Disponível em:< twiki.im.ufba.br/pub/MAT052/EscritorLivreDeContexto/artigoCientifico.pdf>.

Acesso em: 22 out. 2018.

Willyard, C. H. e Mccless, C. W. (1987) "Motorola's technology roadmapping Process". Research Management, set-oct, 1987, p.13-19.

WIPO - World Intellectual Property Organization (2019). Site de Internet. Disponível em: <http://www.wipo.int/classifications/ipc/en/>. Acesso em: 26. Janeiro 2019.

\section{Biografia das Autoras Márcia Ribeiro - http://lattes.cnpq.br/9317391220320437}

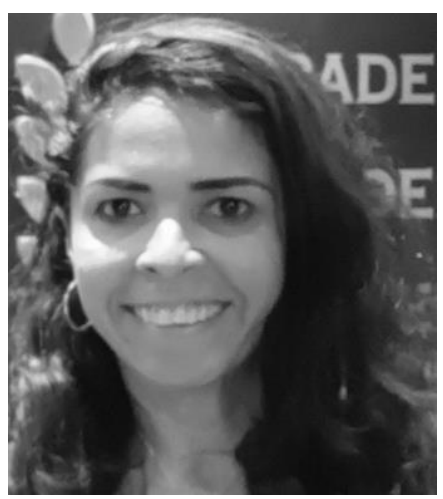

Doutora em Tecnologia de Processos Químicos e Bioquímicos, Márcia é posdoutoranda no Programa de PósGraduação em Informática da UNIRIO. Seus tópicos de pesquisa são: Sistemas de Informação, Inovação e Gestão de Conhecimento. Além disso, em seu doutorado apresentou uma metodologia para a construção de um roadmap aplicado a matérias-primas renováveis. Lotada como Analista de Planejamento e Gestão da Fundação Instituto Brasileiro de Geografia e Estatística (IBGE) atuando na Pesquisa de Inovação Tecnológica (PINTEC).

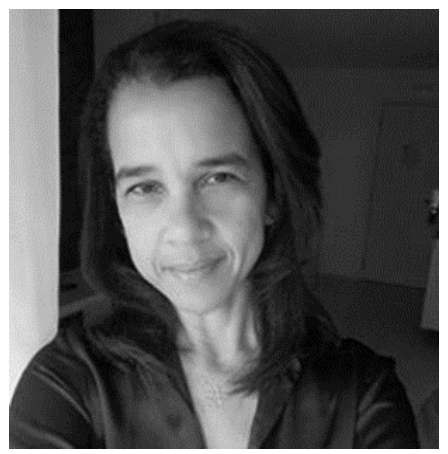

Renata Araujo - http://lattes.cnpq.br/3589012014320121

Doutora em Engenharia de Sistemas e Computação, Renata é professora na Faculdade de Computação e Informática da Universidade Presbiteriana Mackenzie e pesquisadora convidada do Laboratório de Ludologia, Engenharia e Simulação da COPPE/UFRJ. Seus tópicos de pesquisa são: Sistemas de Informação, Democracia e Governança Digital, Gestão de Processos de Negócio e Gestão da Inovação. Nos últimos 4 anos, tem trabalhado para estimular, discutir e gerar conhecimento sobre os processos de inovação e suas relações com a pesquisa científica e o desenvolvimento tecnológico nas universidades e, em particular, pelos programas de pós-graduação no Brasil. Renata é uma das editoras do livro Pesquisa e Inovação, da editora Publ!t (2017). Há 16 anos participa da consolidação da área de Sistemas de Informação no Brasil junto à SBC. 